\title{
Research on the synergism of smoking and periodontal disease in patients with rheumatoid arthritis and diabetes
}

\section{$\mathrm{PhD}$ Thesis}

Emese Battancs D.M.D.

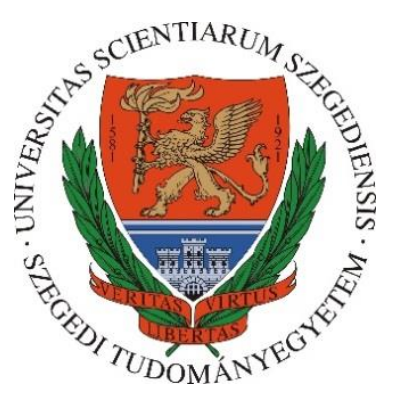

Szeged

2021 


\title{
Research on the synergism of smoking and periodontal disease in patients with rheumatoid arthritis and diabetes
}

\author{
$\mathrm{PhD}$ Thesis \\ Doctoral School of Clinical Medicine \\ Dental research \\ Dr. Emese Battancs D.M.D.
}

\author{
Supervisor: \\ Dr. habil. Márk Antal Ph.D., MSc. \\ Dr. habil. Zoltán Baráth Ph.D., MSc.
}

Department of Operative and Esthetic Dentistry

Department of Prosthodontics

Faculty of Dentistry

University of Szeged 


\section{Publications}

I.

Emese Battancs, Dorottya Gheorghita, Szabolcs Nyiraty, Csaba Lengyel, Gabriella Eördegh, Zoltán Baráth, Tamás Várkonyi, Márk Antal

Periodontal Disease in Diabetes Mellitus : A Case-Control Study in Smokers and Non-Smokers DIABETES THERAPY , 14 p. (2020)

IF: 3.179

II.

Mark Antal, Emese Battancs, Marta Bocskai, Gabor Braunitzer, Laszlo Kovacs

An observation on the severity of periodontal disease in past cigarette smokers suffering from rheumatoid arthritis-evidence for a long-term effect of cigarette smoke exposure? BMC ORAL HEALTH, 18. Paper 82-7 p. ISSN 1472-6831 (2018)

IF: 2.048

\section{Presentations related to the subject of the thesis}

Battancs Emese, Antal M., Baráth Z.

Szisztémás betegségek és a parodontitisz kapcsolata a dohányzás tükrében

In: Antibacterial and mucolytic therapy in cystic fibrosis and Research in oral cavity from basic science to clinical use Symposium

(2018) p. 52

Battancs Emese, Bocskai Márta, Braunitzer Gábor, Eördegh Gabriella, Kovács László, Antal Márk

A periodontális betegség súlyossága korábban dohányzó rheumatoid arthritises betegeknél bizonyíték a dohányzás hosszú távú hatásáról Paper: 7 (2017)

Szegedi Fogorvos Találkozó és Tudományos Konferencia, [poszter] 


\section{Contents}

I. Abbreviations _____________________________________________________ 4

II. Introduction___________________________________ 6

Rheumatoid arthritis __________________________________ 7

Diabetes mellitus ______________________________ 9

Periodontitis ______________________________________________ 11

Smoking ____________________________________________________ 14

III. Aims of the study ____________________________________ 16

IV. Material and Methods ______________________________________ 17

V. Results_______________________________________________ 23

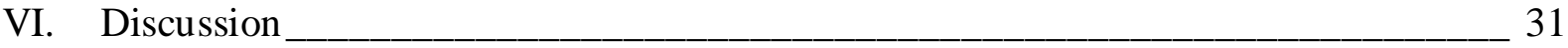

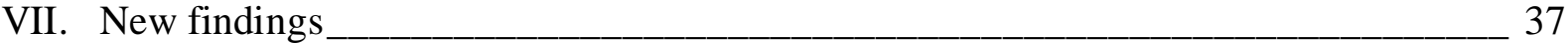

VIII. Summary___________________________________________ 38

IX. Acknowledgment _____________________ 50

X. Publications_______________________________ 51 


\section{Abbreviations}

- $\quad$ AAP- American Academy of Periodontology

- $\quad$ ACPA- anti-citrullinated peptide antibody

- $\quad$ aMCV- anti-mutated citrullinated vimentin

- $\quad$ BMI- body mass index

- $\quad$ BOP - bleeding on Probing

- $\quad$ CAL- clinical attachment loss

- $\quad$ CNS- control never smoked

- $\quad$ CRP- c-reactive protein

- $\quad$ CS- control, used to smoke

- $\quad$ DAS28-ESR- disease activity score

- DM- diabetes mellitus

- $\quad$ DMARD- disease modifying anti-rheumatic drug

- $\quad$ DNA- deoxyribonucleic acid

- $\quad$ EBV-Epstein-Barr virus

- $\quad$ ELISA- enzyme-linked immunosorbent assay

- HAQ-DI- health assessment questionnaire disability index

- $\quad \mathrm{HBV}$ - hepatitis B virus

- HbA1c-hemoglobin A1c

- $\quad \mathrm{HCV}$ - hepatitis $\mathrm{C}$ virus

- $\quad$ HIV-human immunodeficiency virus

- $\quad$ HPV- human papilloma virus

- HLA- human leukocyte antigen

- IDF- International Diabetes Federation

- $\quad$ IFN $\gamma$ - interferon gamma

- $\quad$ IL- interleukin

- $\quad$ LPS- lipopolysaccharides

- $\quad$ MMP- matrix metalloproteinase

- $\quad$ NK- natural killer cell

- $\quad$ NSC-non-smokers without diabetes

- $\quad$ NSDM- non-smoker diabetic patients group 
- OHI-S-Simplified Oral Health Index

- $\quad$ PMN-polymorphonuclear leukocytes

- $\quad$ PD- periodontal disease

- $\quad$ PG- prostaglandin

- $\quad$ PNS- patient never smoked

- $\quad$ PPD- probing depth

- $\quad$ PS- patient, used to smoke

- $\quad$ RA- rheumatoid arthritis

- $\quad$ RANK- receptor activator of nuclear factor $\kappa \mathrm{B}$

- $\quad$ RANKL- receptor activator of nuclear factor $\kappa B$ ligand

- RF- rheumatoid factor

- $\quad$ ROS- reactive oxygen species

- $\quad$ SC-smoker controll group

- $\quad$ SDM- smoking diabetic patients group

- $\quad$ TNF- tumor necrosis factor

- WHO- World Health Organization 


\section{Introduction}

The concept of immunity has been known since Ehrlich (1) considered it as a protection against infections. Now it is well-known that immune processes are much more complex, involving recognition, information transfer and executive functions.

The immune system is divided into two types, innate and adaptive immune systems.

When a pathogen crosses the physicochemical line of defense, it first encounters elements of the innate immune system. Once pathogens enter the body, they initiate elimination processes such as phagocytosis and activation of the complement and cytokine systems. The role of macrophages is to recognize and ingest pathogens, followed by release of alarm cytokines. These are interleukins, such as interleukin 1 (IL-1) and tumor necrosis factor- $\alpha$ (TNF- $\alpha$ ), causing blood flow increase and recruitment of active nonspecific immune cells at the site of infection. In response to IL-6, hepatocytes produce acute phase proteins. In response to pathogens, cytokines (TNF- $\alpha$, IL-1, IL-6, IL-12) and complement peptides C3a as well as C5a are produced, which activate cellular and humoral elements.

After ingestion of the pathogen, local inflammation develops: neutrophils appear first, followed by monocytes, which differentiate into macrophages after being activated by cytokines and chemokines. These so called inflammatory cells play an important role in innate immunity.

In certain circumstances, this innate protection is not enough. In this case, immature dendritic cells with the ingested pathogen migrate into the nearest lymph node. Meanwhile, dendritic cells mature and present pathogen-derived peptides on their MHC molecules to Th cells. Th cells interact with matching B cells, get activated, and start to divide. In response to cytokines released by Th cells, B cells transform to antibody-producing plasma cells, and the antibodies released initiate mechanisms leading to elimination of pathogens (predominantly bacteria). Cytokines produced by Th cells also induce Tc cell maturation to destructive lymphocytes, making the elimination of virus-infected cells possible. It is important to emphasize that during adaptive immune response, $\mathrm{T}$ and $\mathrm{B}$ memory cells are also formed, whereas in case of reinfection, no memory effect can be expected in innate immunity (2).

Periodontal pathogenic bacteria and individual immune response both play a role in the development of periodontal disease. Therefore it is also important to overview basic immunological processes that explain the relationship between inflammatory reactions, being either periodontal or systemic in origin. 
The aim of our study was to evaluate the relationship and interdependence between periodontal and systemic diseases.

Periodontal conditions and systemic diseases influence each other (3). The most investigated conditions are cardiovascular diseases (4), rheumatoid arthritis (RA) (5), and diabetes mellitus (DM) (6-8). Other studies showed relationship with hypertension (8), osteoporosis (9), psoriasis $(10,11)$, pulmonary diseases (12), and complications in pregnancy and around delivery (13-16).

The aim of our study is to evaluate the relationship between systemic diseases, including diabetes mellitus and rheumatoid arthritis, and periodontal disease. We investigated the effect of smoking on diabetes, rheumatoid arthritis, and periodontal disease.

\section{Rheumatoid arthritis}

RA is an inflammatory autoimmune disease involving several organs and organ systems. It is characterized by synovitis resulting bone and cartilage destruction causing deterioration of joint functionality and mobility.

The disease involves $0.5-1 \%$ of the adult population with an onset at around the age of 35 50 years (17).

In the susceptibility to RA, human leukocyte antigens (HLAs) play a crucial role. In patients with HLA-DR4, the course of the disease is unfavourable; therefore, these genes are of prognostic significance. In genetically susceptible individuals, the disease is triggered by external environmental factors. In RA, triggering factors (infective antigens) may include viruses (hepatitis B virus (HBV), hepatitis C virus (HCV), Epstein-Barr virus (EBV), human immunodeficiency virus (HIV), human papilloma virus (HPV) vaccination) and bacteria (mycobacterium, E. coli, Chlamydia) $(18,19)$.

In recent years, several true autoantibodies were detected in RA. Amongst these, anti-cyclic citrullinated peptide (anti-CCP), antifilaggrin, and antiperinuclear factor can be pathognomonic early in the disease process (20). Genetic predisposition, environmental factors, and autoimmune phenomena together trigger inflammation of the synovium (synovitis). In synovitis, inflammatory leukocytes (initially neutrophil granulocytes, followed by $\mathrm{T}$ cells and monocytes/macrophages) flow out through the vessel wall into the extravasal space and synovium. In arthritis, synovium is composed of $\mathrm{T}$ cells accumulated in the 
interstitium, interstitial macrophages, fibroblasts, lymphocytes, and a large number of small vessels formed as a result of enhanced angiogenesis. Amongst proinflammatory cytokines, tumor necrosis factor alpha (TNF- $\alpha$ ), interleukin 1 (IL-1), IL-6, and IL-8 play a crucial role in the initiation and propagation of the inflammatory process. C-reactive protein (CRP) is increased in RA. Some cytokines (e.g., TNF- $\alpha$ and IL-1), enzymes (e.g., matrix metalloproteinases: collagenase, stromelysin), and prostanoids (e.g., prostaglandin $\mathrm{E}_{2}$ ) produced by inflammatory cells destroy cartilage covering the end of the bones forming the joints and also the bone itself (21). Receptor activator of nuclear factor $\kappa B$ (RANK)-RANK ligand (RANKL) interaction plays a key role in osteoclast activation and bone erosion. RANKL is an important cytokine in the development and activation of osteoclasts. It is secreted by osteoblasts and stromal cells and binds to its receptor RANK expressed on the surface of osteoclast (22). RANK-RANKL interaction plays a crucial role in bone resorption, metabolic bone diseases, arthritis, and malignant bone tumors (23). A change in oxygen metabolism is seen and inflammation results in production of reactive oxygen species (ROS). ROS exert harmful effects on nucleic acids, proteins, and lipids by initiating a redox cascade (24).

Natural killer cells (NK) are prominent components of the innate immune response and because of their ability to secrete a variety of cytokines they could have a disease-promoting or a disease-controlling role in autoimmune diseases including RA. It has been suggested that NK cells can play both a protective and a pathogenic role in rheumatoid arthritis. The interplay between NK cells and other cells of natural and specific immunity will occur through release of cytokines. One of the most potent osteoclastogenic cytokines which is pivotal in the pathogenesis of RA is TNF- $\alpha$. In RA, decreased NK cell activity has been observed (25).

Several studies have evaluated the relationship between RA and periodontal disease. As shown by Pischon et al, there is a positive correlation between RA and periodontal disease (26). The periodontal pathogen, Porphyromonas gingivalisis expresses the citrullinating enzyme peptidyl-arginine deiminase (PPAD). Compared to the general population, subjects with periodontal disease (PD) are at an increased risk of developing RA, and vice versa, which suggests that once they are established, they mutually aggravate each other (27). 


\section{Diabetes mellitus}

Based on International Diabetes Federation's (IDF) data, the prevalence of DM in 2014 was $8.5 \%$ in the 20 to 79 age group, projected to reach 592 millions in 2035 (28).

Types of diabetes:

1. type 1
a. autoimmune
b. idiopathic

2. type 2

3. gestational

4. other (e.g., diseases of the exocrine pancreas, endocrinopathy, genetic disturbances in insulin effect)

In type 1 diabetes, the pancreas is unable to produce enough insulin, which is mainly the result of an autoimmune process continuously destructing pancreatic beta cells (29). Environmental factors combined with genetic susceptibility are thought to contribute to the development of the disease. In genetically susceptible individuals, still mostly unknown environmental factors trigger cellular autoimmunity, which specifically targets pancreatic beta cells and causes their death. Certain viruses may play a role in disease development, such as Coxsackievirus B, rotavirus, mumps virus, and cytomegalovirus (30). In the development of diabetes some publications have also raised the role of $\mathrm{HCV}, \mathrm{EBV}$, varicella zoster, rubella, retrovirus (31).

The autoimmune Type 1 diabetes is a T cell-mediated disease. The process occurring in the islets of Langerhans is accompanied by the appearance of one or more autoantibodies to different beta cell antigens. Macrophages are also critical mediators of islet inflammation due to their ability to secrete cytokines, such as IL- $1 \beta$ and TNF- $\alpha$ and ROS. The three cytokines that seem to be implicated in the inflammation of pancreatic beta cells in T1D are the synergic action of interferon gamma (IFN- $\gamma$ ) and the innate inflammatory cytokines TNF- $\alpha$ and IL-1 $\beta(32)$.

Type 2 diabetes is most often related to obesity, sedentary lifestyle, and calory overconsumption. In addition to environmental factors, genetic predisposition also plays a role in disease development. Kim et al showed that NK cell activity is decreased in poorly controlled type 2 diabetes (33). 
Oxidative stress facilitates ROS production, and due to elevated proinflammatory cytokine and chemokine levels, beta cell function is impaired.

IL-6 together with other inflammatory cytokines induces apoptosis in pancreatic islets, resulting in progression of $\mathrm{T} 2 \mathrm{D}$. TNF- $\alpha$ plays and essential role in creating a linkage among pancreatic islet cells, insulin resistance, and obesity. Its overproduction in adipose tissue maintains inflammation in the pancreas, causes beta cell death, and produces additional insulin resistance in peripheral tissues (32).

Patients with T2DM have more immature bone cells precursors, with increased number of osteoclasts and decreased osteoblasts, confirming low bone turnover and reduced cytokines (34). In T1DM, serum RANKL level found significanty increased (35). In T2DM, the number of NK cells is increased, as shown in a 2020 study (36).

Diabetes mellitus has several complications. These include retinopathy, nephropathy, neuropathy, macrovascular abnormalities, prolonged wound healing, and periodontitis (37). $\mathrm{DM}$ is one of the main risk factors for developing chronic kidney disease. Diabetic nephropathy is the most common cause of end stage renal disease, contributing to approximately $45 \%$ of new cases, and is also an independent risk factor for cardiovascular disease $(38,39)$.

Recent studies have shown that an interrelation between inflammation and metabolic abnormalities in diabetes leads to endothelial injury and the development of vascular complications. It has been suggested that the early indicator of these effects is endothelial dysfunction together with the development of a pro-coagulant state $(40,41)$. The increased expression of inflammatory cytokines and adhesion molecules can amplify the inflammatory responses, leading to an aggravation of diabetic vascular complications. Also, proinflammatory cytokines TNF- $\alpha$, IL-1 and IL- 6 are important to mediate the pro-coagulant effect of damaged endothelial cells (38).

In hyperglycemia, IL-1 $\beta$, matrix metalloproteinase 8 (MMP-8), and MMP-9 levels are elevated (42).

Many researchers focus on the relationship between DM and periodontitis. Due to cytokines and mediators involved in both diseases, these two conditions affect each other probably by worsening symptoms and disease manifestation vice versa. 
A strong correlation was found between periodontitis and DM (43-45) as well as between periodontitis and the metabolic control of DM both in type 1 and type 2 diabetes (46-52). However, not all results support these findings with certainty: in a 3-year follow-up study, Joshipura did not find a relationship between DM and periodontitis $(53,54)$. Some authors believe that the relationship is two-way (55-57), and therefore they hypothesize that periodontal therapy may influence DM (58) (59). A positive effect of periodontal therapy on DM outcomes was observed $(59,60)$, but results are either contradictory or not sufficiently detailed (61).

\section{Periodontitis}

Periodontitis is a chronic, destructive oral condition characterized by supporting tissue inflammation, which results in progressive loss of adhesion and bone (62). Its major symptom is clinical attachment loss (CAL), radiologically detectable bone destruction and is accompanied by pocket formation and gingival bleeding.

Dental plaque accumulation increases the number of polymorphonuclear leukocytes (PMN) within a few days. PMNs release proteolytic enzymes causing tissue destruction, formation of plasma cell-rich scar tissue, and decrease of gingival collagen content, and the number of lymphocytes increases within 20 days (63).

In periodontitis, bacterial strains of the oral biofilm interfere with the body's defense mechanisms. Bacteria have both direct and indirect effects. Direct destruction is mediated by proteolytic enzymes and endotoxins. Their indirect effect exerted via endotoxins (lipopolysaccharides (LPS)) may trigger a strong immune reaction. Activation of the immune system results in inflammation and immune response $(64,65)$. Inflammatory cytokines play an important role in the initiation of immune response. They attract PMN to the site of inflammation, stimulate osteoclasts and bone resorption, increase production of the collagendegrading enzyme MMP, and inhibit bone formation. By affecting the bone marrow, they increase the number of white blood cells and stimulate macrophage functions. The level of $\mathrm{C}$ reactive protein and prostaglandin $\mathrm{E}_{2}\left(\mathrm{PGE}_{2}\right)$ is elevated. PGEs enhance the effect of inflammatory cytokines, stimulate MMP production, and induce bone resorption. At the same time, IL-1 $\beta$ and TNF- $\alpha$ levels also increase (66). An increase in the presence and 
concentration of these inflammatory mediators can also be observed in diabetes mellitus (67, $68)$.

The pathological changes occurring during progression of chronic periodontitis are summarized in a 2009 publication by Ohlrich et al (69).Table 1.

An increase in PMN count and TNF alfa can already be observed in the initial lesion. In the progressive lesion, B cell response dominates, IL-1 és IL-6 are increased, and connctive tissue lost and bone breakdown is seen.

In the advanced lesion, high levels of IL-6, TNF and $\mathrm{PGE}_{2}$ stimulate fibroblasts and macrophages to produce more MMP. PG enhances the effect of inflammatory mediators which induce edema and stimulate MMP production. MMPs are classified into six subgroups. From a parodontological point of view, collagenase subgroup consisting of MMP-1, MMP-8, and MMP-13 is of particular importance. MMPs can modulate the severity and progression of periodontitis. Granulocytes released during periodontal tissue inflammation activate and secrete MMP-8. Activated enzymes degrade the collagen layer of dense connective tissue, thereby immune cells, including granulocytes, macrophages, and osteoclasts, can reach the source of inflammation. $90-95 \%$ of collagenolytic activity of sulcus fluid is originated from MMP-8 (70).

RANKL expression in periodontal tissues is a very complicated process that involves many factors. RANKL is identified in lymphocytes, stromal cells, and many other cell types in periodontal tissues which play an important role in direct or indirect regulatory roles.

According to the study of Wilensky published in 2000, the number and effect of NK cells is questionable. Based on immunohistochemistry results, some authors deny interaction (71). However, positive correlation is more likely. According to Fijita and Stelin, the number of NK cells is increased in periodontitis $(72,73)$. This finding is supported by in vitro experiments, where the number of NK cells is elevated in the presence of periodontopathogenic bacteria (P. gingivali, A. actinomycetemcommitans, F. nucleatum (74, 75). Periodontitis induces excessive ROS production in periodontal tissue, clinical studies have shown that periodontitis is correlated with increased lipid peroxidation in gingival crevicular fluid (76). 
Cytokines such as IL-1 $\beta$ and TNF- $\alpha$ can upregulate RANKL expression in periodontal cells and increase osteoclast formation (77).

\begin{tabular}{|l|l|}
\hline Initial lesion & $\begin{array}{l}\text { Up to } 4 \text { days following plaque accumulation. Polymorphonuclear leukocytes (PMN), } \\
\text { complement activation, loss of connective tissue. Mast cells release tumor necrosis } \\
\text { factor alpha, PMNs migrate into the gingival sulcus, but as the bacteria are protected } \\
\text { by the biofilm, abortive phagocytosis occurs. PMNs release lysosomalcontents, } \\
\text { which leads to further tissue destruction }\end{array}$ \\
\hline $\begin{array}{l}\text { Early } \\
\text { lesion }\end{array}$ & $\begin{array}{l}7-21 \text { days after plaque accumulation, clinically evident approximately from Day 12. } \\
\text { Dominantly macrophages and lymphocytes } \quad \text { CD4+CD8+2:1).Perivascular } \\
\text { inflammatory infiltrate. Intercellular spaces between epithelial cells widen, bacterial } \\
\text { products infiltrate the gingival tissues at a higher rate. Escalation of response. If } \\
\text { plaque is removed, tissue remodeling can take place }\end{array}$ \\
\hline $\begin{array}{l}\text { Established/Progressive } \\
\text { lesion }\end{array}$ & $\begin{array}{l}\text { Dominantly B cell/plasma cell response. High levels of IL-1 and IL-6: connective } \\
\text { tissue loss, bone breakdown }\end{array}$ \\
\hline Advanced lesion & $\begin{array}{l}\text { Overt loss of attachment. High levels of IL-1, TNFaand PGE2 stimulate fibroblasts } \\
\text { and macrophages to produce matrix metalloproteases. The junctional epithelium } \\
\text { progresses in apical direction (deepening periodontal pocket) }\end{array}$ \\
\hline
\end{tabular}

Table 1.: The immunpathogenesis of chronic periodontitis (Olrich et al. 2009)

New periodontal classification:

The 2018 classification introduced a number of modifications to the 1999 American Academy of Periodontology (AAP) classification. At the initial examination, staging is done, which describes severity. Grading describes disease progression, biological background, the effect of periodontitis on general health, and risk factors, such as diabetes mellitus or smoking (78). Determinants of clinically healthy periodontium include health status and smoking as internal and external environmental factors, respectively.

We started our study before publication of the new classification, therefore the at that time relevant, accepted classification was used. The 2018 classification has high clinical specificity. Many variables are to be considered (4 stages, 3 classes, and many other modification factors), therefore it is difficult to use for epidemiological studies. Moreover, due to the many groups and classes, it is difficult to perform interpretable statistical analyses. 


\section{Smoking}

Smoking is a global public health issue and is defined by World Health Organization (WHO) as one of the most important risk factors of oral cancer. In 2015, over 1.1 billion people smoked tobacco, which was the cause of more than one in ten deaths worldwide, killing alltogether above 6 million people. Although smoking prevalence and the caused morbidity so as mortality seem to be falling in most rich countries, but there is a predilection in low- and middle-income countries for future mortality increase. Worldwide a total of 933 million people, so as 1 in 4 men are estimated to be daily smokers, whereas 4/5th of these individuals live in low- and middle income countries (79).

Smoke not only induces airway and lung inflammation, but also systemic cellular and humoral inflammation and oxydative stress, significantly changes vasomotor and endothelial function, and increases concentration of several coagulation factors. These systemic effects of smoking lead to the development of chronic conditions, such as cardiovascular and metabolic diseases and malignancies induced by smoking (80).

Smoking modulates immune function in many ways: it inhibits bactericidal function of macrophages and neutrophils and production of several proinflammatory cytokines, suppresses primary immune response, and causes T cell anergy (81). These effects can favor the occurrence of infections considered as risk factors for both RA and DM, such as Coxsackievirus B, rotavirus, mumps virus, and cytomegalovirus, $\mathrm{HBV}, \mathrm{HCV}$, and $\mathrm{EBV}$.

Oxidative substances released from tobacco smoke (ROS) damage epithelial cells lining the airways by inducing peroxidation of lipids and other cell membrane constituents, activate oxidative-sensitive cellular pathways, and induce deoxyribonucleic acid DNA damage (82).

ROS activate epithelial cell intracellular signaling cascades that lead to inflammatory gene activation IL-8 and TNF $\alpha$. The secretion of these inflammatory mediators promotes chronic immune cell recruitment and inflammation.

Smoke suppresses certain T helper 1 responses and facilitates Th2 inflammatory reactions. Cozen et al found elevated levels of IL-13 and IL-5 in smokers (83).

In smokers, less NK cells are produced. The role of NK cells is the body's innate protection against microbes and cells underwent malignant transformation. In smokers, cytotoxic effects of NK cells decrease (84).

Interferons (type 1 IFN $\alpha$ and $-\beta$ and type 2 IFN $\gamma$ ), IL-18, and TNF also stimulate NK cells. In smokers, MMP-8 levels are also elevated (85). Smoking modulates the RANK/RANKL system, and cigarette smokers tend to have higher serum concentrations of RANKL (86). 
Smoking has a direct harmful effect on the periodontium, and nicotine negatively affects fibroblasts. Due to the negative effect of nicotine on circulation, the intensity of gingivitis is always lower in smokers (87).

Bacteriology examinations have shown that in smokers, periodontopathogenic microorgansims appear earlier and in larger proportion (88).

Smoking affects immunity, promotes colonization of periodontopatogenic bacteria and locally acts as an irritant.

It is obvious that inflammatory processes are performed via the same routes and mediators when the systemic diseases we reviewed, periodontal disease, and smoking are present. Thus it seems clear that these conditions closely affect and aggravate each other. Table 2. summarizes mediators involved in the discussed systemic diseases and smoking.

\begin{tabular}{|c|c|c|c|c|c|}
\hline & $\begin{array}{c}\text { Inflammatory cytokines } \\
\text { (IL-1, IL-6, TNF-a) }\end{array}$ & $\begin{array}{c}\boldsymbol{R O S} \\
\uparrow\end{array}$ & $\begin{array}{c}M M P \\
\uparrow\end{array}$ & $\begin{array}{l}\text { Changes in } \\
\text { NK activity }\end{array}$ & $\begin{array}{c}\text { RANK/RANKL } \\
\text { modifications }\end{array}$ \\
\hline $\mathrm{DM}$ & $\begin{array}{c}\text { DMT1: TNF } \alpha, \text { IL-1 } \beta, \text { IL- } \\
6 \\
\text { DMT2: TNF } \alpha, \text { IL-6 }\end{array}$ & & & $\begin{array}{r}\text { NK cell } \\
\text { number } \uparrow\end{array}$ & RANKL $\uparrow$ \\
\hline RA & $\begin{array}{c}\mathrm{TNF} \alpha, \mathrm{IL}-1, \mathrm{IL}-6, \mathrm{IL}-8 \\
\mathrm{PGE}_{2}\end{array}$ & & & $\begin{array}{c}V_{\mathrm{NK}} \\
\text { activity } \downarrow\end{array}$ & RANKL $\uparrow$ \\
\hline $\mathrm{PD}$ & IL-8, TNF $\alpha$, PMN & & & questionable & $V_{\text {RANKL } \uparrow}$ \\
\hline Smoking & TNF $\alpha$, IL-8, IL-5, IL-13 & & & & RANKL $\uparrow$ \\
\hline
\end{tabular}

Table 2.: Diabetes mellitus (DM), rheumatoid arthritis (RA), periodontal disease (PD), and mediators in smokers

As the above shown table suggests, these diseases might have a strong connection. Therefore, we wanted to test these hypotheses, if these connections can be also seen in patients suffering in DM or RA and PD. Also as the role of smoking is quite unmapped yet, and as the theoretical background suggests, this might play an essential role in the worsening of these conditions. 


\section{Aims of the study}

\section{Rheumatoid arthritis}

1. We wished to find out about if smoking acts as a booster of periodontal deterioration also in the context of RA. Later this hypothesis was modified to previous smokers.

2. We hypothesized that the periodontal status of patients with no smoking history would be significantly poorer than that of healthy controls (the effect of RA).

3. We were also interested in the relationship between rheumatological factors and periodontal status.

\section{Diabetes mellitus}

1. We hypothesized that the periodontal status of patients with DM with no smoking history would be significantly poorer than that of healthy non-smoking controls, and that periodontal status in the former would be further exacerbated by smoking.

2. We aimed to find out if periodontal status is different in patients with type 1 and type 2 diabetes.

3. We aimed to investiagte, the relationship between glycemic control and periodontal disease. 


\section{Material and Methods}

\section{$\underline{\text { Rheumatoid arthritis }}$}

Our study had three observed parameters: rheumatoid arthritis, periodontal disease, and smoking.

\section{Patients, exclusion criteria}

RA patients were recruited from among the patients of the Department of Rheumatology, University of Szeged. The control group was recruited from among people attending mandatory lung screening in the same city and the same period. The study was approved by the Institutional and Regional Ethics Committee for Medical Biological Researchat the University of Szeged (approval No.144/2014), and the study design conformed to the Declaration of Helsinki in all respects. Demographic and tobacco use data were collected by a questionnaire. Written informed consent was obtained from all participants.

Demographic and tobacco use data were collected by a questionnaire. Participants were divided into four demographic groups.
1. CNS - control, never smoked
2. CS - control, used to smoke
3. PNS - patient, never smoked
4. PS-patient, used to smoke

Exclusion criteria were determined based on the literature of the subject and included obesity (body mass index - BMI $\geq 30 \mathrm{~kg} / \mathrm{m}^{2}$ ), excessive alcohol consumption, drug abuse, diabetes mellitus, diseases causing neutropenia and local or systemic inflammatory conditions (other than RA) (89). Those patients who should receive antibiotic prophylaxis or those who received antibiotics within 2 weeks prior to study initiation and patients wearing orthodontic braces were also excluded from the study.

Pregnant women, patients receiving oncological therapy, toothless patients or patients with less than 3 teeth were excluded from the study. Poor oral hygiene, defined as Simplified Oral Health Index (OHI-S)- > 3 was also an exclusion criterion. For the Simplified Oral Hygiene 
Index, only six surfaces (from four posterior and two anterior teeth) are examined for debris and calculus (90).

\section{Rheumatological parameters}

To characterize the patient population from a rheumatological point of view, the following indices and laboratory values were recorded: $\operatorname{IgM}$ rheumatoid factor seropositivity and levels (RF) measured with nephelometry, anti-citrullinated peptide antibody (ACPA) seropositivity and levels with antigenic specificity to anti-mutated citrullinated vimentin (aMCV) measured with enzyme-linked immunosorbent assay (ELISA), disease activity score (DAS28-ESR) at the latest visit and its average of the past 12 months, and the health assessment questionnaire disability index (HAQ-DI). Data on the conventional and biological disease modifying antirheumatic drug (DMARD) and corticosteroid therapy of the patients were also recorded. Laboratory values were determined as part of the routine examinations (i.e. not especially for this study).

\section{Periodontal parameters}

We used the staging proposed by Fernandes and colleagues (62). The reason for using this classification was that its clinical staging matches the pathological/pathophysiological changes in PD very well (69), and that our research team already had experience with it (11). The staging requires the following parameters to be recorded: bleeding on probing (BOP; the presence or absence of bleeding within $15 \mathrm{~s}$ after probing), probing depth (PPD; in millimeters), and clinical attachment loss (CAL; distance of the cemento-enamel junction from the bottom of the pocket). All subjects received a full-mouth examination and their periodontal status was classified into one of the four categories of the staging:

1. Healthy: no clinical attachment loss (CAL) or bleeding on probing (BOP)

2. Early periodontitis: $\mathrm{CAL} \geq 1 \mathrm{~mm}$ at $\geq 2$ teeth

3. Moderate periodontitis: $\mathrm{CAL} \geq 4 \mathrm{~mm}$ at 3 locations and $\mathrm{PPD} \geq 3 \mathrm{~mm}$ in at least 2 locations

4. Severe/manifest periodontitis: $\mathrm{CAL} \geq 6 \mathrm{~mm}$ at $\geq 2$ teeth and $\mathrm{PPD} \geq 5 \mathrm{~mm} \geq$ at 1 location. 
For the examination, Williams probes (Hu-Friedy Manu-facturing Co., Chicago, USA) were used.

\section{Smoking parameters}

Tobacco use data were collected by a questionnaire. Our study design was to identify smoking and non-smoking groups, but our patients turned out to be non-smokers. We managed to find only a few (8 in total) smoker RA patients; therefore, study parameters were modified.

The majority of our patient sample consisted of non-smokers and former smokers. Former smoking was defined as smoking for at least 10 years.

\section{Statistical analysis}

Required sample size was calculated with $\mathrm{G}^{*}$ Power 3.1.5. (University of Kiel, Germany), a software designed especially for statistical power and sample size computation (91). The software allows the computation of achieved statistical power (post-hoc) and required sample size (a priori). As mostly categorical variables were to be analyzed, a priori sample size estimation was performed for cross tabs/chi square/contingency tables, with the following input parameters: effect size (w): 0.3; $\alpha$ : 0.05; power (1- $\beta)$ : 0.9; df: 3 .

Within-group analyses (Mann-Whitney U tests) were also performed in the patient group, according to the smoking status. For the analyses, SPSS 21.0 (IBM,USA) was used. 


\section{$\underline{\text { Diabetes mellitus }}$}

\section{Patients, exclusion criteria}

Diabetic patients were recruited form the 1st Department of Internal Medicine of the University of Szeged, Faculty of General Medicine, Albert Szent-Györgyi Medical Centre, and the control group was recruited from among people attending mandatory lung screening in the same city and the same period. Before enrollment, all participants were informed about the study. Participation was voluntary, and written informed consent was obtained from each participant.

The protocol of the study conformed to the tenets of the Declaration of Helsinki in all respects, and it was approved by the Regional Research Ethics Committee for Medical Research at the University of Szeged, Hungary (144/2014-B/001, accepted 2014, modified in 2019). Participants were divided into four groups.

1. SDM - smoker diabetic patients group

2. NSDM - non-smoker diabetic patients group

3. SC - smoker control group

4. NSC - non-smoker control group

The exclusion criteria for all groups were determined based on relevant literature and included obesity (BMI $\geq 30 \mathrm{~kg} / \mathrm{m}^{2}$ ), excessive alcohol consumption, drug abuse, rheumatoid arthritis and diseases causing neutropenia and local or systemic inflammatory conditions (other than DM) (89). Poor oral hygiene, defined as a Simplified Oral Health Index (OHI-S) score $>3$ (90) was also an exclusion criterion. Pregnant women, patients receiving cancer therapy, toothless patients or patients with $<3$ teeth, patients with a serum creatinine level $\geq$ $1.6 \mathrm{mg} / \mathrm{dL}$, and patients with hemoglobinopathy or any other type of hemorrhagic disorder were excluded from the study. Patients in need of antibiotic prophylaxis for any reason or who had received antibiotics within 2 weeks prior to study initiation were also excluded, as were individuals wearing orthodontic braces. 


\section{Diabetological parameters}

Control of diabetes was estimated by measuring hemoglobin A1c (HbA1c) levels in the peripheral blood (92). Glucose bound to hemoglobin indicates the amount of the glycemic control. As the lifespan of red blood cells is 8 to 12 weeks, actual HbA1c level reflects the average blood glucose level approximately in the last 3 months. Accordingly, laboratory examinations are performed every 3 months, therefore diabetes control of the last 9 months was determined from the last 3 measurements. Patients were assigned into 3 groups based on the arithmetic mean of the last 3 measurements (62).

1. Well-controlled, if $\mathrm{HbA} 1 \mathrm{c}$ is $\leq 7 \%$

2. Moderately controlled, if $\mathrm{HbA} 1 \mathrm{c}$ is $>7.01 \%$ and $\leq 8.5 \%$

3. Poorly controlled, if $\mathrm{HbA} 1 \mathrm{c}$ is $>8.5 \%$

\section{Periodontal parameters}

Periodontal status of the patients was assessed by full oral examination, where probing depth: PPD (distance between the marginal gingiva and the bottom of the periodontal pocket), bleeding on probing: BOP, clinical attachment loss: CAL (distance of the cemento-enamel junction from the bottom of the pocket), and the amount of plaque were evaluated. Probing depth, bleeding, clinical attachment loss, and the amount of plaque was measured at six locations per tooth (mediobuccally, buccally, distobuccally, distolingually, lingually, and mediolingually) except for the wisdom teeth (which were not evaluated in this study). Williams probes (Hu-Friedy Manufacturing Co. Chicago, USA) were used.

For the assessment of periodontal status, the same classification and periodontal characteristics were used as described previously in the rheumatoid arthritis- periodontal parameters section.

From an immunological/pathological aspect, two stages (healthy/early and moderate/severe) can be distinguished based on the main pathomechanisms. The reason for using this classification was that its clinical staging is in line with the pathological/pathophysiological changes in PD (69). Therefore, data recorded on the basis of Fernandes classification were treated as binary (mild/severe) variables. 


\section{Smoking parameters}

Smoking habits were evaluated by using a self-administered questionnaire. A smoker was defined as a person who reported smoking at least two cigarettes for an uninterrupted period of 1 year prior to study initiation. A non-smoker was defined as a person with no self-reported tobacco use for 30 years prior to study initiation. Former smokers were not included in the sample.

\section{Statistical analysis}

Statistical analyses were performed in SPSS version 21.0 statistical software (IBM Corp., Armonk, NY, USA). Continuous variables were described as means $\pm \mathrm{SD}$, and categorical variables were characterized as frequencies. For hypothesis testing, one-way analysis of variance (ANOVA; with Tukey's post-hoc test) or Kruskal-Wallis ANOVA (with MannWhitney $U$ tests for the pairwise comparisons) were used, depending on whether the normality and homogeneity assumptions were fulfilled. To test the association between categorical variables, we used the chi-square test. If a significant association was found, the dataset was further analyzed with Kruskal-Wallis ANOVA (with Mann-Whitney $U$ tests for the pairwise comparisons). The general limit of significance was set at $p=0.05$, but it was corrected for multiple comparisons with the Bonferroni correction where necessary. 


\section{Results}

\section{$\underline{\text { Rheumatoid arthritis }}$}

\section{Demographic and tobacco use characteristic}

As we mentioned, we defined four demographic groups.

The demographic and tobacco use characteristics of the four studied groups are given in Table 3. It can be seen that the vast majority of the participants were females. This is because RA affects predominantly women and the control group was selected to match the patient group age- and gender-wise as closely as possible.

\begin{tabular}{|c|c|c|c|c|c|}
\hline Group & $\begin{array}{c}\text { Sex ratio } \\
\mathrm{F}(\%): \mathrm{M}(\%)\end{array}$ & $\begin{array}{c}\text { Smoke-free for } \\
\text { (mean years, SD) }\end{array}$ & $\begin{array}{c}\text { Smoked for } \\
\text { (mean years, SD) }\end{array}$ & $\begin{array}{c}\text { Cigarettes } \\
\text { smoked per } \\
\text { day (rounded } \\
\text { average, SD) }\end{array}$ & $\begin{array}{c}\text { Age in years } \\
(\text { mean, SD) }\end{array}$ \\
\hline CNS (n= 55) & $44(80): 11(20)$ & NA & NA & NA & $55.7(13.3)$ \\
\hline CS (n= 22) & $12(54): 10(45)$ & $11.3(12.5)$ & $13.8(10.2)$ & $11(7.9)$ & $58.1(13.5)$ \\
\hline PNS (n= 42) & $33(79): 9(21)$ & NA & NA & NA & $56.5(12.7)$ \\
\hline PS (n=31) & $24(77): 7(23)$ & $16.4(12.2)$ & $18.3(11.4)$ & $14(10.2)$ & $59.3(13.6)$ \\
\hline
\end{tabular}

\section{Table 3.: Demographic and tobacco use characteristics}

CNS control, never smoked, CS control, used to smoke, PNS patient, never smoked, $P S$ patient, used to smoke

The within-group comparisons in the patient group did not indicate significant difference in any of the rheumatological indices between former smoking and non-smokers. To test the effect of RF positivity on periodontal status, a separate multinomial regression analysis was conducted. While no statistically significant effects were found, seropositivity for RF increased the odds of the moderate stage to 1.65 , and that of the severe stage to 2.51 . The rheumatological indices of the patient group are summarized in Table 4. 


\begin{tabular}{|c|c|c|}
\hline Rheumatoid factor positivity $[>30 \mathrm{U} / \mathrm{ml}] \mathrm{n}(\%)$ & FS & $20(64.5)$ \\
\hline Anti-citrullinated peptide antibody positivity & NS & $24(57.1)$ \\
\hline$[>20 \mathrm{U} / \mathrm{ml}] \mathrm{n}(\%)$ & $\mathrm{FS}$ & $20(64.5)$ \\
\hline Patients on conventional DMARD therapy n $(\%)$ & NS & $25(59.5)$ \\
\hline Patients on biological DMARD therapy n $(\%)$ & NS & $36(80.6)$ \\
\hline DAS28 at visit mean (SD; range) & NS & $17(54.8)$ \\
\hline Average DAS28 in the previous 12 months mean & FS & $(n=21) 3.10(1.42 ; 0.97-6.52)$ \\
\hline (SD; range) & NS & $(n=35) 2.94(1.30 ; 0.79-6.33)$ \\
\hline HAQ mean (SD) & NS & $(n=8) 2.41(1.30 ; 1.20-5.30)$ \\
\hline & FS & $(n=15) 0.98(0.84)$ \\
\hline & NS & $(n=7) 2.21(0.70)$ \\
\hline
\end{tabular}

Table 4.: Rheumatological characterization of the patient population by smoking in patient history

FS former smoker, NS never smoked, DMARD disease-modifying antirheumatic drug, DAS28 disease activity score, HAQ score on the health assessment questionnaire for rheumatoid arthritis. Where data from not all patients were available, the actual number of patients is given in parentheses

The periodontal status and CAL data of each group is shown in Table 5. It is noteworthy that while the majority of the cases in both control groups falls into the healthy and early stages, in the patient groups the situation is just the opposite. This tendency is the most remarkable among the patients who used to smoke. $81 \%$ of them were classified as having moderate or severe PD. Note also that in the patient groups nobody was found who could be classified as periodontally healthy.

When assessing CAL values, it can be concluded that highest values are observed in the PS group, followed by PNS and control groups. 


\begin{tabular}{|c|c|c|c|c|c|c|c|c|}
\hline \multirow[b]{2}{*}{ Total } & \multicolumn{4}{|c|}{ Rheumatoid arthritis } & \multicolumn{4}{|c|}{ Control } \\
\hline & \multicolumn{2}{|c|}{$\mathrm{n}=73$} & \multicolumn{2}{|c|}{$\begin{array}{c}\text { CAL } \\
3.55( \pm 1.62)\end{array}$} & \multicolumn{2}{|c|}{$\mathrm{n}=77$} & \multicolumn{2}{|c|}{ CAL 2.03( \pm 1.17$)$} \\
\hline & \multicolumn{2}{|c|}{$P N S$} & \multicolumn{2}{|c|}{$P S$} & \multicolumn{2}{|c|}{ CNS } & \multicolumn{2}{|c|}{$C S$} \\
\hline Total & $n=42$ & $\begin{array}{c}\text { CAL } \\
3.18 \\
( \pm 1.39)\end{array}$ & $\mathrm{n}=31$ & $\begin{array}{c}\text { CAL } \\
4.06 \\
( \pm 1.79)\end{array}$ & $\mathrm{n}=55$ & $\begin{array}{c}\text { CAL } \\
2.08 \\
( \pm 1.26)\end{array}$ & $n=22$ & $\begin{array}{c}\text { CAL } \\
1.91 \\
( \pm 0.89)\end{array}$ \\
\hline Healthy & 0 & NA & 0 & NA & $\begin{array}{c}8 \\
(15)\end{array}$ & $\begin{array}{c}0.67 \\
( \pm 0.30)\end{array}$ & $\begin{array}{c}4 \\
(18)\end{array}$ & $\begin{array}{c}0.76 \\
( \pm 0.89)\end{array}$ \\
\hline Early & $\begin{array}{l}12 \\
(29)\end{array}$ & $\begin{array}{c}1.81 \\
( \pm 0.21)\end{array}$ & $\begin{array}{c}6 \\
(19)\end{array}$ & $\begin{array}{c}1.89 \\
( \pm 0.31)\end{array}$ & $\begin{array}{c}30 \\
(55)\end{array}$ & $\begin{array}{c}1.52 \\
( \pm 0.39)\end{array}$ & $\begin{array}{c}12 \\
(55)\end{array}$ & $\begin{array}{c}1.76 \\
( \pm 0.37)\end{array}$ \\
\hline Moderate & $\begin{array}{c}22 \\
(52)\end{array}$ & $\begin{array}{c}3.07 \\
( \pm 0.32)\end{array}$ & $\begin{array}{c}12 \\
(39)\end{array}$ & $\begin{array}{c}3.50 \\
( \pm 0.89)\end{array}$ & $\begin{array}{c}13 \\
(24)\end{array}$ & $\begin{array}{c}3.35 \\
( \pm 0.21)\end{array}$ & $\begin{array}{c}5 \\
(23)\end{array}$ & $\begin{array}{c}3.19 \\
( \pm 0.25)\end{array}$ \\
\hline Severe & $\begin{array}{c}8 \\
(19)\end{array}$ & $\begin{array}{c}5.52 \\
( \pm 1.21)\end{array}$ & $\begin{array}{c}13 \\
(42)\end{array}$ & $\begin{array}{c}5.57 \\
( \pm 1.46)\end{array}$ & $4(7)$ & $\begin{array}{c}4.99 \\
( \pm 0.14)\end{array}$ & $1(5)$ & $\begin{array}{c}4.72 \\
( \pm \mathrm{NA})\end{array}$ \\
\hline
\end{tabular}

Table 5.: Periodontal status of the participants, according to Fernandes et al.(62)

Data are given as $n$ (\%, rounded percantages), CAL (mm, mean $\pm S D)$

The results of the multinomial regression analysis are given in Table 6. The analysis indicated no significant influence of either age or sex on periodontal status. Male sex appears to be associated with an increased risk for both the moderate and the severe stages, but given the under-representation of the male sex in this study, we would not draw conclusions from this. As for the odds of developing the moderate or severe stages, these were significantly higher in both patient groups for both stages as compared to controls who never smoked.

Controls who used to smoke did not have significantly higher odds to develop any of these stages than controls who never smoked, while an increment was definitely seen. The highest significant odds ratio for the severe stage $(16,25)$ was found in the RA group of FS. 


\begin{tabular}{|c|c|c|c|c|c|c|}
\hline $\begin{array}{l}\text { Periodontal status } \\
\text { (reference: early) }\end{array}$ & & B & $\mathrm{df}$ & Sig. & $\operatorname{Exp}(B)$ & $95 \%$ Clfor $\operatorname{Exp}(B)$ \\
\hline \multirow{6}{*}{ moderate } & PS & 1.529 & 1 & 0.011 & 4.616 & $1.423-14.966$ \\
\hline & PNS & 1.442 & 1 & 0.003 & 4.231 & $1.623-11.030$ \\
\hline & CS & 0.932 & 1 & 0.090 & 2.538 & $0.866-7.442$ \\
\hline & CNS & - & - & - & - & - \\
\hline & Male sex & 0.223 & 1 & 0.643 & 1.250 & $0.487-3.212$ \\
\hline & Age & 0.002 & 1 & 0.896 & 1.002 & \\
\hline \multirow{6}{*}{ severe } & PS & 2.788 & 1 & 0.000 & 16.250 & $3.917-67.412$ \\
\hline & PNS & 1.609 & 1 & 0.022 & 5.000 & $1.265-19.762$ \\
\hline & $\mathrm{CS}$ & 0.405 & 1 & 0.666 & 1.500 & $0.238-9.465$ \\
\hline & CNS & - & - & - & - & - \\
\hline & Male sex & 0.839 & 1 & 0.867 & 2.315 & $0.703-7.619$ \\
\hline & Age & 0.028 & 1 & 0.176 & 1.029 & $0.972-1.033$ \\
\hline
\end{tabular}

Table 6.: Results of the multinomial regression analysis

The odds ratios $(\operatorname{Exp}(B))$ express the odds that a member of the given group develops the given stage of periodontal disease. Controls who never smoked and early stage periodontal disease served as reference (as no periodontally healthy individuals were found in the patient group, healthy could not be used as reference). B: correlation coefficient; df: degrees of freedom 


\section{$\underline{\text { Diabetes mellitus }}$}

\section{Selected groups}

A total of 128 participants were enrolled into the study. Subjects were assigned into four main study groups, as mentioned earlier in the material and methods.

Each group consisted of 32, age- and sex-matched participants. Participants of the control group came for screening, and they had no systemic diseases. Exclusion criterias have also been mentioned earlier.

Diabetic patients were compared to age- and sex-matched controls, and both type 1 and type 2 diabetic patients were investigated. Mean age was 44.36 and 58.3 years for type 1 and type 2 diabetes, respectively. The following table (Table 7.) summarizes the resulting demographic and tobacco use characteristics and the periodontal status in the examined groups according to Fernandes et. al (62).

\begin{tabular}{|l|l|l|}
\hline & \multicolumn{1}{|c|}{ Diabetes patient groups } & \multicolumn{1}{c|}{ Control groups } \\
\hline Age & & $54.0 \pm 13.6$ \\
\hline Smoker subsample & $54.5 \pm 13.4$ & $54.5 \pm 13.9$ \\
\hline Non-smoker subsample & $54.3 \pm 13.9$ & \\
\hline Sex ratio & & $20 \mathrm{~F}: 12 \mathrm{M}(62.5 \%: 37.5 \%)$ \\
\hline Smoker subsample & $18 \mathrm{~F}: 14 \mathrm{M}(56.25 \%: 43.75 \%)$ & $22 \mathrm{~F}: 10 \mathrm{M}(68.75 \%: 31.25 \%)$ \\
\hline Non-smoker subsample & $18 \mathrm{~F}: 14 \mathrm{M}(56.25 \%: 43.75 \%)$ & \\
\hline CAL (mm) & & $2.51 \pm 1.32$ \\
\hline Smoker subsample & $2.94 \pm 1.60$ & $2.50 \pm 1.24$ \\
\hline Non-smoker subsample & $2.83 \pm 1.51$ & \\
\hline PDD (mm) & & $2.27 \pm 1.06$ \\
\hline Smoker subsample & $2.60 \pm 1.25$ & $2.30 \pm 0.98$ \\
\hline Non-smoker subsample & $2.71 \pm 1.28$ & \\
\hline Number of teeth $(\mathbf{n})$ & & $19.2 \pm 7.5$ \\
\hline Smoker subsample & $16 \pm 8.0$ & $20.7 \pm 5.7$ \\
\hline Non-smoker subsample & $18 \pm 7.9$ & NA \\
\hline T1D subsample & $22 \pm 6.5$ & NA \\
\hline T2D subsample & $16.2 \pm 7.7$ & \\
\hline
\end{tabular}

Table 7.: Descriptive statistics of patient and control groups

Values in table are presented as the mean \pm standard deviation (SD) or as frequencies (number of observations with the percentage in parenthesis) CAL Clinical attachment level (distance between the cemento-enamel junction and the bottom of the pocket), $F$ female, $M$ male, PPD probing pocket depth (distance between the marginal gingiva and the bottom of the periodontal pocket), T1D/T2D type 1/type 2 diabetes 
Group membership was significantly associated with the severity of PD $\left(\chi^{2}=36.910\right.$, $p=0.000$; see also Table8. Subsequent analysis of the data using Kruskal-Wallis ANOVA revealed significant variance across the four groups in terms of severity of PD ( $H$ $(3)=25.659, p=0.000)$. The pairwise comparisons showed a significant difference in severity of PD between the SC and NSC groups $(p=0.027)$ and between the NSC and SDM groups $(p=0.000)$; the difference between the NSDM and SDM groups was nearly significant $(p=0.052)$. Of note is that no one in the two smoker groups was classified as having good periodontal health. As shown in Table 8., the significant between-group differences most probably were due to differences in the frequency of the severe stage of PD across the groups, with the lowest frequency of severe PD found among those in the NSC group (15.6\%), followed in increasing order of frequency among those in the NSDM group (28.1\%) and SC group $(31.3 \%)$, peaking in the SDM group (62.5\%). The other stages of PD did not show such notable between-group differences (apart from the already mentioned healthy stage, but the frequency of this stage was quite low in all groups). It is remarkable that while the stages of PD followed a normal distribution in the healthy, non-smoking controls, smoking seemed to cause a shift toward the middle of the severity spectrum, and when smoking was combined with DM, a marked shift toward the most severe stage was observed.

Pairwise comparisons (Tukey's HSD [honestly significant difference] test) indicated that patients in the SDM group had significantly fewer teeth (mean \pm SD: $16.0 \pm 7.9$ ) than subjects in the NSC group $(20.7 \pm 5.6)$ at $p=0.02$. No other comparison returned a significant result. There was stepwise difference in the mean number of teeth between groups, with patients in the SDM group having the lowest mean number of teeth and subjects in the NSC group having the highest (see also Table 7). In terms of the number of teeth by DM type, patients with T1D had significantly more teeth than patients with T2D (22 \pm 6.5 vs. $16.2 \pm 7.7 ; p=0.01)$. 


\begin{tabular}{|l|l|l|l|l|}
\hline \multicolumn{1}{|c|}{ Study groups } & $\begin{array}{c}\text { Healthy } \\
\text { periodontal } \\
\text { status }\end{array}$ & Early PD & Moderate PD & Severe PD \\
\hline NSC & $4(12 \%)$ & $11(34 \%)$ & $12(37 \%)$ & $5(16 \%)$ \\
\hline SC & $0(0.0 \%)$ & $3(9 \%)$ & $19(59 \%)$ & $10(31 \%)$ \\
\hline NSDM & $2(6 \%)$ & $2(6 \%)$ & $19(59 \%)$ & $9(28 \%)$ \\
\hline SDM & $0(0.0 \%)$ & $1(3 \%)$ & $11(34 \%)$ & $20(63 \%)$ \\
\hline
\end{tabular}

Table 8.: Severity of periodontal disease by study group, according to Fernandes et al.(62)

Values in table are presented as the frequency (number with percentage in parentheses) PD periodontal disease

Study groups categorized by periodontal disease: SDM, smoking patients with DM; NSDM, nonsmoking patients with DM; SC, smokers without DM (control group); NSC, non-smokers without DM (control group)

\begin{tabular}{|l|l|l|l|l|}
\hline HbA1c status & $\begin{array}{c}\text { Healthy } \\
\text { periodontal status }\end{array}$ & \multicolumn{1}{|c|}{ Early PD } & \multicolumn{1}{c|}{ Moderate PD } & \multicolumn{1}{c|}{ Severe PD } \\
\hline WC & $1(6.3 \%)$ & $0(0.0 \%)$ & $9(56.3 \%)$ & $6(37.5 \%)$ \\
\hline MC & $1(4 \%)$ & $2(8.0 \%)$ & $12(48 \%)$ & $10(40 \%)$ \\
\hline PC & $0(0.0 \%)$ & $1(4.3 \%)$ & $9(39.1 \%)$ & $13(56.5 \%)$ \\
\hline
\end{tabular}

Table 9.: Severity of periodontal disease by glycemic control as assessed by hemoglobin Alc status

Values in table are presented as the frequency (number with percentage in parentheses) Hemoglobin Alc (HbAlc) status: WC (well-controlled): HbAlc $\leq 7 \% ; M C$ (moderately controlled): HbAlc $>7.01 \%, \leq 8.5 \%$; PC (poorly controlled): HbAlc $>8.5 \%$

\section{Diabetes Type, Glycemic Control and Periodontal Status}

There was no significant association between the type of diabetes (T1D or T2D) and periodontal status $\left(\chi^{2}=6.190, p=0.103\right)$, and the distribution of the four stages of periodontal status was almost the same in these two diabetic subgroups, with the exception that severe PD was $17.5 \%$ more frequent in the T2D subgroup than in the T1D subgroup. However, T2D was over-represented in the study sample $\left(n_{\text {type } 2}=42\right.$ vs. $\left.n_{\text {type } 1}=22\right)$, so the validity of this observation cannot be established with safety. There was also no significant association between diabetes control and the severity of $\operatorname{PD}\left(\chi^{2}=15.503, p=0.078\right)$, but the results of the 
analysis suggest that the frequency of the severe stage increased with the worsening of diabetes control ( $n_{\text {well controlled }}=6 ; n_{\text {moderate }}=10 ; n_{\text {mpoorly controlled }}=13$; see Table 9 .).

A significant difference in the severity of PD was found between the SC and NSC groups $(p=0.027)$ and between the NSC and SDM groups $(p=0.000)$, while the difference between the NSDM and SDM groups approached significance $(p=0.052)$. No person in the smoker groups could be classified as having a healthy periodontal status. The four-stage classification followed a normal distribution in the healthy, non-smoking controls (NSC). Smoking caused a shift toward medium-severe PD, while a marked shift toward the most severe stage was observed when both smoking and DM were present (SDM). There was no significant association between the type of DM and periodontal status, nor between diabetes control and the severity of PD. Persons in the SDM group had significantly fewer teeth than those in the NSC group (mean \pm standard deviation: $16.0 \pm 7.9$ vs. $20.7 \pm 5.6 ; p=0.02$ ). 


\section{Discussion}

During our research plans, we wanted to understand more detailed the connection between periodontal disease and the two selected general medical condition, RA and DM. With a special focus on the effect of smoking in both research groups, our results have shown interesting aggravative effects.

\section{$\underline{\text { Rheumatoid arthritis }}$}

A relationship was hypothesized between RA factors, past smoking, and periodontal status. We found that past smoking did not have a significant effect on any of the rheumatological indices and that there was no association between these indices and periodontal status. The lack of the effect of past smoking on the rheumatological status as expressed by these indices might be best explained by the time passed since the patient stopped smoking. While cigarette smoke must have been an extra immunological stimulus when the patient was still smoking, and it might as well have boosted the immunological memory against citrullinated proteins (93), these effects are unlikely to be reflected in indices characterizing a much narrower time window.

Although our results were not statistically significant, the aggravating effect of former smoking is obvious. By examining nearly 700 RA patients, Stolt et al found that after smoking cessation, it takes at least 10 years for the risk of developing RA and RF positivity to decrease significantly (94). In a 14-year follow-up study involving smoker and former smoker RA patients, Heliövaara reached to a similar conclusion. It is expected that the number of patients developing RA is higher in the former smoker group than in the healthy control group (95).

It was interesting to see that only 8 RA patients smoked; the reason for this can be that patients try to do as much as they can for decreasing joint pain and improving quality of life. When patients are warned about the harmful, disease-aggravating effect of smoking, they quit this habit.

Our other hypothesis was that RA is a risk factor for periodontal disease. Many studies are investigating this relationship. In an epidemiological study of Smit, patients with RA had a higher incidence of periodontal disease than individuals without RA (96). 
Mercado pointed out that PD has been known as a risk factor for RA and vice versa (97), and our results demonstrate the same: the presence of RA itself is enough to significantly increase the odds that the patient will develop a more severe stage of PD. Our hypothesis was correct.

We were also interested in the relationship between rheumatological factors and periodontal status.

No association was found between the specific RA indices and the periodontal status, while, as pointed out before, being in the RA group in itself significantly increased the odds of the more severe PD stages. Research is contradictory. In 2019, Rahim et al reached to the same conclusion. They did not find significant associations between elevated rheumatoid factor, anti-citrullinated protein antibody, or active rheumatoid arthritis disease with the presence of chronic periodontitis (98). In a 2017 study, the importance of periodontal pathogenic bacteria and rheumatoid parameters in the relationship between periodontitis and RA remained unclear (99). Other studies describing larger populations found significant association with rheumatoid factor positivity and anti-citrullinated peptide antibody production $(100,101)$.

We think that our sample size was probably too small to allow reliable assessment at the level of the individual indices, considering their greater variability.

The main finding of this study, that the former smoker RA patients had the highest and significant odds ratio for the severe stage of PD is really an unexpected one. From the results it appears that the effect is not mediated by the actual rheumatological status, the presence of RA with a longer period of cigarette smoke exposure in the past is enough. The main finding of our study is that smoking has a very strong effect even after cessation. In 2006, Costenbader evaluated the effect of smoking and past smoking in RF-positive and RFnegative RA patients. He found that the relative risk of RA was significantly elevated among current and past smokers, compared with never smokers and the risk of incident RA remained substantially elevated until 20 years after smoking cessation (102).

This suggests that long-term cigarette smoking might permanently sensitize the periodontium, but at this point we could only speculate about the possible mechanisms, and it is because of that reason that we put this up for debate. 


\section{$\underline{\text { Diabetes mellitus }}$}

In the past 70 years, many studies had been published where the interaction between DM and PD was investigated. PD is a frequent sequela of diabetes, so much so that Harald Löe termed it "the sixth complication of diabetes mellitus" $(37,103)$. However, it can also be concluded that via inflammatory mediators, bad periodontal condition results in decreased beta cell function and thus increases the risk of developing DM (104).

It is well established in the literature that smoking is a major risk factor for developing and aggravating DM and its complications. Both smoking and DM are modifying factors of periodontal status (105). In diabetic patients, the harmful effect of smoking is also confirmed by the increased prevalence of macrovascular complications (106).

Our initial hypothesis was that smoking has an aggravating effect on periodontal status and severity, and this effect is even stronger if an additional systemic background, DM is present.

The results are clear in the sense that that while periodontal status followed a normal distribution in healthy, non-smoking controls, smoking caused a shift toward the middle of the PD spectrum, and when smoking was combined with diabetes, a marked shift toward the most severe stage was seen. This result was expected, as it is known that smoking damages the periodontal tissues even in otherwise healthy persons and has a detrimental effect on the progression of PD (107). We considered it therefore safe to hypothesize that smoking would turn out to be even more detrimental when the primary disease, itself known to have the ability to initiate (and probably aggravate) PD, is present. Within the limits of the present study, we believe we have verified this hypothesis. However, the data gathered in this study do not allow an explanation of how exactly DM and smoking interact to aggravate PD. As such, the results may be interpreted as evidence to support the existence of such a detrimental interaction. In 2018, Tarnowski made and interesting observation when comparing smokers with type 1 diabetes with non-smoker diabetic patients. BOP was lower in the smoker group, demonstrating the negative effect of smoking on microvascular circulation (108).

We also hypothesized that the periodontal status of diabetic patients with no smoking history would be significantly poorer than that of healthy non-smoking controls. With our hypothesis, we suggested that DM can cause and worsen periodontitis, which means that periodontal status of diabetic patients is presumably worse than that of patients with no diabetes. 
We believed that this hypothesis was logical based on the established relationship between DM and PD. However, it would appear that the results of our study fail to bear this out; for example, there was no remarkable difference between the NSC and NSDM groups (except for the early stage, but not in general). We do not believe that these results should be interpreted as evidence against the well-established relationship $(89,109)$; rather, the explanation most likely lies in technical factors and is related to the method of assessment and the different ways in which DM and smoking exert their detrimental effect on the periodontium. Smoking, in fact, can be regarded as repeated episodes of an aggressive chemical attack against the tissues. Smoking damages the periodontal tissues in both systemic and local ways (107), with smoking-induced periodontal inflammation always being the more severe type. Diabetes, on the other hand, develops over a course of time and seems to exert its effects on periodontal tissues effects more slowly and in finer, less direct ways. To give just one expressive example, the antibacterial capacity of the saliva can be downregulated in persons with DM over time, which favors the growth of periodontopathogenic bacterial species (110). The end result is that while smoking has a rapid effect on the periodontium and maintains a high level of severe inflammation through repeated exposure of these tissues to toxic chemicals, severe stages of periodontal inflammation in DM develop later in the course of the disease and the inflammation is milder than that induced by smoking. As the classification we used measures the actual severity of the periodontal inflammatory process, it is not surprising that it cannot show the fine DM-related difference as efficiently as the massive difference caused by smoking. Still, it should be noted that the classification does not fail to capture the effect of DM entirely: our results clearly show that when smoking is paired up with DM, the destruction of the periodontium is significantly more severe. In summary, DM has a damaging effect on the periodontium, but the clinical staging we used to assess the severity of the inflammation is less sensitive to the effects of DM.

We wanted to know if periodontal status is influenced by the presence of T1D or T2D. A very limited number of publications is available on the effect of T1D on periodontium; Tervonen studied the relationship between PD and T1D (111). Since little is known about the relationship between the different types of diabetes and the periodontium, we addressed this issue as well.

In terms of the effect of diabetes type, our results suggest that T2D may be more damaging to the periodontium than T1D, as reflected by the mean number of teeth and the relatively 
higher prevalence of the most severe stage in participants with T2D. However, the sample size was not large enough for us to allow firm conclusions and, in addition, T2D was overrepresented (which is realistic but not optimal for the comparison of the two types). As for the lower number of teeth in patients with T2D, it cannot be excluded that the observed tooth loss is the result of lifestyle rather than the DM itself, given that an unhealthy diet is a major risk factor for the development of T2D. A possible explanation for the lower teeth number in T2D is mean age, since it is 14 years higher than in T1D. According to the literature, the number of teeth decreases with age $(112,113)$.

Glycemic control is another factor was found not to significantly influence the severity of PD (or vice versa), although the descriptive statistics clearly show that glycemic control became poorer with increasingly severe stage of PD. Taken together, it would appear that there is an effect of glycemic control on PD (in either direction), but that this effect is either statistically non-significant or significant but with too small an effect size to show significance in this sample size. The literature is divided over this question but leans more toward the no-effect side. A number of earlier studies with sample sizes similar to our sample size, such as the study of Fernandes and colleagues (62), have also failed to show a significant association between PD severity and glycemic control. In their review, Taylor and colleagues also concluded that there is no such connection (114). However, there are also studies supporting the counter-argument, providing strong evidence that HbA1c improved as a result of periodontal treatment (115). A possible explanation for the obvious uncertainty of this results is that while $\mathrm{HbA1c}$ is a well-established clinical parameter that helps treatment, it primarily allows the assessment of the risk of microvascular complications (116). While microvascular factors may contribute to the deterioration of periodontal status in DM, PD is still predominantly a disease of immunological/microbiological origin. In short, while our results seem to support the existence of a weak connection, $\mathrm{HbA1c}$ might not be the best parameter to link DM with PD.

We can draw one valid conclusion: smoking damages even the healthy periodontium, but when a DM patient smokes, the destruction multiplies. This is quite similar to what our research group described about the relationship between smoking and PD in psoriasis (11). In that study, we concluded that smoking and psoriasis act in synergy to boost periodontal inflammation, which in turn leads to the over-representation of the most severe stage in smoking patients. The situation appears to be the same in the case of diabetes, i.e. the 
relatively mild damaging effect of the disease itself is multiplied by the repeated chemical challenge of cigarette smoke exposure. How this effect is realized goes beyond the scope of this study, but it is safe to assume that the process has both microvascular and immunological components, and it is probably the meeting of these different pathogenic pathways that gives rise to the observed massive deterioration. Some studies have addressed the issue of the effect of smoking and DM on periodontal health (117-119), but none of these concentrated explicitly on the interaction of the two factors so far. In a study published in January of 2020, the interaction between smoking, DM, and PD was investigated via inflammatory cytokines. The authors concluded that DM induces proinflammatory state in PD and smoking initiates immunosuppression. When these two factors, DM and smoking are combined, smoking with its stronger effect decreases proinflammatory effect (120). Our results are new in this respect and demonstrate another way in which smoking can do further damage to the health of patients with DM. 


\section{New findings}

\section{$\underline{\text { Rheumatoid arthritis }}$}

The main finding of our study is that even past smoking has a strong effect on the periodontal status of RA patients. Independently from the actual rheumatological status of the patient and presence or absence of RA, smoking causes severe periodontal abnormalities even after cessation. Thus permanent smoking exerts its harmful, irreversible effect on the periodontium after cessation.

\section{Diabetes mellitus}

This study confirmed that smoking has an aggravating effect on periodontal status and severity, and this effect is even stronger if an additional systemic background, DM is present.

We also confirmed, that the aggravating effect of DM alone is weaker than the aggravating effect of smoking. 


\section{Summary}

In this thesis we investigated the relationship between systemic diseases (rheumatoid arthritis and diabetes), smoking, and periodontal diseases. Smoking or past smoking was of major importance in both studies. This is the factor that most negatively affects the periodontium and it is an unfavourable prognostic factor in definitive disease. It is without any doubt that both rheumatoid arthritis and diabetes aggravate periodontal disease, but not as much as smoking. We demonstrated that if any of the above mentioned systemic disease and smoking is present simultaneously, the worst periodontal prognosis can be expected.

In patient care, it is important to emphasize and explain the harmful local and systemic effects of smoking. Due to the investigated connections smoking cessation is essential for treatment. At the same time, dentists also have a great responsibility to find out about the patient's current general health before starting a periodontal treatment and to provide the patient with adequate, targeted therapy, as these factors affect each other. Continuous monitoring, follow-up, and coordinated work of treating physicians are important. 


\section{References}

1. Bordon Y. The many sides of Paul Ehrlich. Nature Immunology. 2016;17(1):S6-S.

2. Kany S, Vollrath JT, Relja B. Cytokines in Inflammatory Disease. International journal of molecular sciences. 2019;20(23).

3. Molloy J, Wolff LF, Lopez-Guzman A, Hodges JS. The association of periodontal disease parameters with systemic medical conditions and tobacco use. Journal of clinical periodontology. 2004;31(8):625-32.

4. Aarabi G, Schnabel RB, Heydecke G, Seedorf U. Potential Impact of Oral Inflammations on Cardiac Functions and Atrial Fibrillation. Biomolecules. 2018;8(3).

5. Cheng Z, Meade J, Mankia K, Emery P, Devine DA. Periodontal disease and periodontal bacteria as triggers for rheumatoid arthritis. Best Pract Res Clin Rheumatol. 2017;31(1):19-30.

6. Lagervall M, Jansson L. Relationship between tooth loss/probing depth and systemic disorders in periodontal patients. Swed Dent J. 2007;31(1):1-9.

7. Linden GJ, Lyons A, Scannapieco FA. Periodontal systemic associations: review of the evidence. Journal of clinical periodontology. 2013;40 Suppl 14:S8-19.

8. Arigbede AO, Babatope BO, Bamidele MK. Periodontitis and systemic diseases: A literature review. Journal of Indian Society of Periodontology. 2012;16(4):487-91.

9. Mashalkar VN, Suragimath G, Zope SA, Varma SA. A Cross-Sectional Study to Assess and Correlate Osteoporosis and Periodontitis among Postmenopausal Women: A Dual Energy X-Ray Absorptiometry Study. J Midlife Health. 2018;9(1):2-7.

10. Yamada J, Amar S, Petrungaro P. Psoriasis-associated periodontitis: a case report. Journal of periodontology. 1992;63(10):854-7.

11. Antal M, Braunitzer G, Mattheos N, Gyulai R, Nagy K. Smoking as a permissive factor of periodontal disease in psoriasis. PloS one. 2014;9(3):e92333.

12. Hobbins S, Chapple IL, Sapey E, Stockley RA. Is periodontitis a comorbidity of COPD or can associations be explained by shared risk factors/behaviors? Int J Chron Obstruct Pulmon Dis. 2017;12:1339-49.

13. Sanz M, Kornman K, working group 3 of the joint EFPAAPw. Periodontitis and adverse pregnancy outcomes: consensus report of the Joint EFP/AAP Workshop on Periodontitis and Systemic Diseases. Journal of periodontology. 2013;84(4 Suppl):S164-9. 
14. Battancs E, Gorzo I, Pal A, Novak T, Eller J, Kokai EL, et al. Pregnant women's oral hygiene knowledge and habits after the second millennium in South-East Hungary. Fogorv Sz. 2011;104(3):75-9.

15. Radnai M, Gorzo I, Nagy E, Urban E, Novak T, Pal A. A possible association between preterm birth and early periodontitis. A pilot study. Journal of clinical periodontology. 2004;31(9):736-41.

16. Marakoglu K, Eke AA, Civi S. Smoking as an important factor increasing risk of Helicobacter pylori. Turk J Gastroenterol. 2008;19(2):133-4.

17. Smolen JS, Aletaha D, McInnes IB. Rheumatoid arthritis. Lancet. 2016;388(10055):2023-38.

18. Li S, Yu Y, Yue Y, Zhang Z, Su K. Microbial Infection and Rheumatoid Arthritis. Journal of clinical \& cellular immunology. 2013;4(6).

19. Pellegrino P, Carnovale C, Pozzi M, Antoniazzi S, Perrone V, Salvati D, et al. On the relationship between human papilloma virus vaccine and autoimmune diseases. Autoimmunity reviews. 2014;13(7):736-41.

20. Greiner A, Plischke H, Kellner H, Gruber R. Association of anti-cyclic citrullinated peptide antibodies, anti-citrullin antibodies, and $\operatorname{IgM}$ and $\operatorname{IgA}$ rheumatoid factors with serological parameters of disease activity in rheumatoid arthritis. Annals of the New York Academy of Sciences. 2005;1050:295-303.

21. Yokota K, Sato K, Miyazaki T, Kitaura H, Kayama H, Miyoshi F, et al. Combination of tumor necrosis factor alpha and interleukin-6 induces mouse osteoclast-like cells with bone resorption activity both in vitro and in vivo. Arthritis \& rheumatology. 2014;66(1):121-9.

22. Geusens P. The role of RANK ligand/osteoprotegerin in rheumatoid arthritis. Therapeutic advances in musculoskeletal disease. 2012;4(4):225-33.

23. Tanaka T, Narazaki M, Masuda K, Kishimoto T. Regulation of IL-6 in Immunity and Diseases. Advances in experimental medicine and biology. 2016;941:79-88.

24. Khojah HM, Ahmed S, Abdel-Rahman MS, Hamza AB. Reactive oxygen and nitrogen species in patients with rheumatoid arthritis as potential biomarkers for disease activity and the role of antioxidants. Free radical biology \& medicine. 2016;97:285-91.

25. Shegarfi H, Naddafi F, Mirshafiey A. Natural killer cells and their role in rheumatoid arthritis: friend or foe? TheScientificWorldJournal. 2012;2012:491974. 
26. Pischon N, Pischon T, Kroger J, Gulmez E, Kleber BM, Bernimoulin JP, et al. Association among rheumatoid arthritis, oral hygiene, and periodontitis. Journal of periodontology. 2008;79(6):979-86.

27. Wegner N, Wait R, Sroka A, Eick S, Nguyen KA, Lundberg K, et al. Peptidylarginine deiminase from Porphyromonas gingivalis citrullinates human fibrinogen and alphaenolase: implications for autoimmunity in rheumatoid arthritis. Arthritis and rheumatism. 2010;62(9):2662-72.

28. Group IDFDA. Update of mortality attributable to diabetes for the IDF Diabetes Atlas: estimates for the year 2011. Diabetes Res Clin Pract. 2013;100(2):277-9.

29. Eisenbarth GS. Type I diabetes mellitus. A chronic autoimmune disease. N Engl J Med. 1986;314(21):1360-8.

30. Filippi CM, von Herrath MG. Viral trigger for type 1 diabetes: pros and cons. Diabetes. 2008;57(11):2863-71.

31. Jun HS, Yoon JW. The role of viruses in type I diabetes: two distinct cellular and molecular pathogenic mechanisms of virus-induced diabetes in animals. Diabetologia. 2001;44(3):271-85.

32. Tsalamandris S, Antonopoulos AS, Oikonomou E, Papamikroulis GA, Vogiatzi G, Papaioannou S, et al. The Role of Inflammation in Diabetes: Current Concepts and Future Perspectives. Eur Cardiol. 2019;14(1):50-9.

33. Kim JH, Park K, Lee SB, Kang S, Park JS, Ahn CW, et al. Relationship between natural killer cell activity and glucose control in patients with type 2 diabetes and prediabetes. J Diabetes Investig. 2019;10(5):1223-8.

34. Sassi F, Buondonno I, Luppi C, Spertino E, Stratta E, Di Stefano M, et al. Type 2 diabetes affects bone cells precursors and bone turnover. BMC Endocr Disord. 2018;18(1):55.

35. Karalazou P, Ntelios D, Chatzopoulou F, Fragou A, Taousani M, Mouzaki K, et al. OPG/RANK/RANKL signaling axis in patients with type I diabetes: Associations with parathormone and vitamin D. Italian journal of pediatrics. 2019;45(1):161.

36. Mxinwa V, Dludla PV, Nyambuya TM, Mokgalaboni K, Mazibuko-Mbeje SE, Nkambule BB. Natural killer cell levels in adults living with type 2 diabetes: a systematic review and meta-analysis of clinical studies. BMC immunology. 2020;21(1):51.

37. Loe H. Periodontal disease. The sixth complication of diabetes mellitus. Diabetes Care. 1993;16(1):329-34. 
38. Domingueti CP, Dusse LM, Carvalho M, de Sousa LP, Gomes KB, Fernandes AP. Diabetes mellitus: The linkage between oxidative stress, inflammation, hypercoagulability and vascular complications. J Diabetes Complications. 2016;30(4):738-45.

39. Karnib HH, Ziyadeh FN. The cardiorenal syndrome in diabetes mellitus. Diabetes Res Clin Pract. 2010;89(3):201-8.

40. Goldberg RB. Cytokine and cytokine-like inflammation markers, endothelial dysfunction, and imbalanced coagulation in development of diabetes and its complications. J Clin Endocrinol Metab. 2009;94(9):3171-82.

41. Foulis AK, Farquharson MA, Meager A. Immunoreactive alpha-interferon in insulinsecreting beta cells in type 1 diabetes mellitus. Lancet. 1987;2(8573):1423-7.

42. Kumar MS, Vamsi G, Sripriya R, Sehgal PK. Expression of matrix metalloproteinases (MMP-8 and -9) in chronic periodontitis patients with and without diabetes mellitus. Journal of periodontology. 2006;77(11):1803-8.

43. Lappin DF, Eapen B, Robertson D, Young J, Hodge PJ. Markers of bone destruction and formation and periodontitis in type 1 diabetes mellitus. Journal of clinical periodontology. 2009;36(8):634-41.

44. Salvi GE, Franco LM, Braun TM, Lee A, Rutger Persson G, Lang NP, et al. Proinflammatory biomarkers during experimental gingivitis in patients with type 1 diabetes mellitus: a proof-of-concept study. Journal of clinical periodontology. 2010;37(1):9-16.

45. Sanz M, Ceriello A, Buysschaert M, Chapple I, Demmer RT, Graziani F, et al. Scientific evidence on the links between periodontal diseases and diabetes: Consensus report and guidelines of the joint workshop on periodontal diseases and diabetes by the International Diabetes Federation and the European Federation of Periodontology. Journal of clinical periodontology. 2018;45(2):138-49.

46. Lim LP, Tay FB, Sum CF, Thai AC. Relationship between markers of metabolic control and inflammation on severity of periodontal disease in patients with diabetes mellitus. Journal of clinical periodontology. 2007;34(2):118-23.

47. Taboza ZA, Costa KL, Silveira VR, Furlaneto FA, Montenegro R, Jr., Russell S, et al. Periodontitis, edentulism and glycemic control in patients with type 2 diabetes: a crosssectional study. BMJ Open Diabetes Res Care. 2018;6(1):e000453.

48. Lalla E, Cheng B, Lal S, Kaplan S, Softness B, Greenberg E, et al. Diabetes mellitus promotes periodontal destruction in children. Journal of clinical periodontology. 2007;34(4):294-8. 
49. Hodge PJ, Robertson D, Paterson K, Smith GL, Creanor S, Sherriff A. Periodontitis in non-smoking type 1 diabetic adults: a cross-sectional study. Journal of clinical periodontology. 2012;39(1):20-9.

50. Costa FO, Miranda Cota LO, Pereira Lages EJ, Soares Dutra Oliveira AM, Dutra Oliveira PA, Cyrino RM, et al. Progression of periodontitis and tooth loss associated with glycemic control in individuals undergoing periodontal maintenance therapy: a 5year follow-up study. Journal of periodontology. 2013;84(5):595-605.

51. Garcia D, Tarima S, Okunseri C. Periodontitis and glycemic control in diabetes: NHANES 2009 to 2012. Journal of periodontology. 2015;86(4):499-506.

52. Kim EK, Lee SG, Choi YH, Won KC, Moon JS, Merchant AT, et al. Association between diabetes-related factors and clinical periodontal parameters in type-2 diabetes mellitus. BMC Oral Health. 2013;13:64.

53. Joshipura KJ, Munoz-Torres FJ, Dye BA, Leroux BG, Ramirez-Vick M, Perez CM. Longitudinal association between periodontitis and development of diabetes. Diabetes Res Clin Pract. 2018;141:284-93.

54. Simpson TC, Weldon JC, Worthington HV, Needleman I, Wild SH, Moles DR, et al. Treatment of periodontal disease for glycaemic control in people with diabetes mellitus. Cochrane Database Syst Rev. 2015(11):CD004714.

55. Casanova L, Hughes FJ, Preshaw PM. Diabetes and periodontal disease: a two-way relationship. Br Dent J. 2014;217(8):433-7.

56. Preshaw PM, Alba AL, Herrera D, Jepsen S, Konstantinidis A, Makrilakis K, et al. Periodontitis and diabetes: a two-way relationship. Diabetologia. 2012;55(1):21-31.

57. Taylor GW. Bidirectional interrelationships between diabetes and periodontal diseases: an epidemiologic perspective. Ann Periodontol. 2001;6(1):99-112.

58. Correa FO, Goncalves D, Figueredo CM, Bastos AS, Gustafsson A, Orrico SR. Effect of periodontal treatment on metabolic control, systemic inflammation and cytokines in patients with type 2 diabetes. Journal of clinical periodontology. 2010;37(1):53-8.

59. Engebretson S, Kocher T. Evidence that periodontal treatment improves diabetes outcomes: a systematic review and meta-analysis. Journal of clinical periodontology. 2013;40 Suppl 14:S153-63.

60. Koromantzos PA, Makrilakis K, Dereka X, Katsilambros N, Vrotsos IA, Madianos PN. A randomized, controlled trial on the effect of non-surgical periodontal therapy in patients with type 2 diabetes. Part I: effect on periodontal status and glycaemic control. Journal of clinical periodontology. 2011;38(2):142-7. 
61. Gay IC, Tran DT, Cavender AC, Weltman R, Chang J, Luckenbach E, et al. The effect of periodontal therapy on glycaemic control in a Hispanic population with type 2 diabetes: a randomized controlled trial. Journal of clinical periodontology. 2014;41(7):673-80.

62. Fernandes JK, Wiegand RE, Salinas CF, Grossi SG, Sanders JJ, Lopes-Virella MF, et al. Periodontal disease status in gullah african americans with type 2 diabetes living in South Carolina. Journal of periodontology. 2009;80(7):1062-8.

63. Brecx MC, Schlegel K, Gehr P, Lang NP. Comparison between histological and clinical parameters during human experimental gingivitis. Journal of periodontal research. 1987;22(1):50-7.

64. Seymour GJ, Powell RN, Davies WI. The immunopathogenesis of progressive chronic inflammatory periodontal disease. J Oral Pathol. 1979;8(5):249-65.

65. Hirschfeld J, Howait M, Movila A, Parcina M, Bekeredjian-Ding I, Deschner J, et al. Assessment of the involvement of the macrophage migration inhibitory factorglucocorticoid regulatory dyad in the expression of matrix metalloproteinase- 2 during periodontitis. Eur J Oral Sci. 2017;125(5):345-54.

66. Kalakonda B, Koppolu P, Baroudi K, Mishra A. Periodontal Systemic ConnectionsNovel Associations-A Review of the Evidence with Implications for Medical Practitioners. Int J Health Sci (Qassim). 2016;10(2):293-307.

67. Graves DT, Kayal RA. Diabetic complications and dysregulated innate immunity. Front Biosci. 2008;13:1227-39.

68. Pham MN, Hawa MI, Pfleger C, Roden M, Schernthaner G, Pozzilli P, et al. Pro- and anti-inflammatory cytokines in latent autoimmune diabetes in adults, type 1 and type 2 diabetes patients: Action LADA 4. Diabetologia. 2011;54(7):1630-8.

69. Ohlrich EJ, Cullinan MP, Seymour GJ. The immunopathogenesis of periodontal disease. Aust Dent J. 2009;54 Suppl 1:S2-10.

70. Al-Majid A, Alassiri S, Rathnayake N, Tervahartiala T, Gieselmann DR, Sorsa T. Matrix Metalloproteinase-8 as an Inflammatory and Prevention Biomarker in Periodontal and Peri-Implant Diseases. Int J Dent. 2018;2018:7891323.

71. Cobb CM, Singla O, Feil PH, Theisen FC, Schultz RE. Comparison of NK-cell (Leu-7+ and Leu-11b+) populations in clinically healthy gingiva, chronic gingivitis and chronic adult periodontitis. Journal of periodontal research. 1989;24(1):1-7. 
72. Fujita S, Takahashi H, Okabe H, Ozaki Y, Hara Y, Kato I. Distribution of natural killer cells in periodontal diseases: an immunohistochemical study. Journal of periodontology. 1992;63(8):686-9.

73. Stelin S, Ramakrishan H, Talwar A, Arun KV, Kumar TS. Immunohistological analysis of CD1a langerhans cells and CD57 natural killer cells in healthy and diseased human gingival tissue: A comparative study. Journal of Indian Society of Periodontology. 2009;13(3):150-4.

74. Kikuchi T, Hahn CL, Tanaka S, Barbour SE, Schenkein HA, Tew JG. Dendritic cells stimulated with Actinobacillus actinomycetemcomitans elicit rapid gamma interferon responses by natural killer cells. Infection and immunity. 2004;72(9):5089-96.

75. Kikuchi T, Willis DL, Liu M, Purkall DB, Sukumar S, Barbour SE, et al. Dendritic-NK cell interactions in P. gingivalis-specific responses. Journal of dental research. 2005;84(9):858-62.

76. Sczepanik FSC, Grossi ML, Casati M, Goldberg M, Glogauer M, Fine N, et al. Periodontitis is an inflammatory disease of oxidative stress: We should treat it that way. Periodontology 2000. 2020;84(1):45-68.

77. Chen B, Wu W, Sun W, Zhang Q, Yan F, Xiao Y. RANKL expression in periodontal disease: where does RANKL come from? Biomed Res Int. 2014;2014:731039.

78. Papapanou PN, Sanz M, Buduneli N, Dietrich T, Feres M, Fine DH, et al. Periodontitis: Consensus report of workgroup 2 of the 2017 World Workshop on the Classification of Periodontal and Peri-Implant Diseases and Conditions. Journal of clinical periodontology. 2018;45 Suppl 20:S162-S70.

79. Bilano V, Gilmour S, Moffiet T, d'Espaignet ET, Stevens GA, Commar A, et al. Global trends and projections for tobacco use, 1990-2025: an analysis of smoking indicators from the WHO Comprehensive Information Systems for Tobacco Control. Lancet. 2015;385(9972):966-76.

80. Gerhardsson de Verdier M. The big three concept: a way to tackle the health care crisis? Proc Am Thorac Soc. 2008;5(8):800-5.

81. Qiu F, Liang CL, Liu H, Zeng YQ, Hou S, Huang S, et al. Impacts of cigarette smoking on immune responsiveness: Up and down or upside down? Oncotarget. 2017;8(1):26884.

82. Lee J, Taneja V, Vassallo R. Cigarette smoking and inflammation: cellular and molecular mechanisms. Journal of dental research. 2012;91(2):142-9. 
83. Cozen W, Diaz-Sanchez D, James Gauderman W, Zadnick J, Cockburn MG, Gill PS, et al. Th1 and Th2 cytokines and IgE levels in identical twins with varying levels of cigarette consumption. J Clin Immunol. 2004;24(6):617-22.

84. Mian MF, Lauzon NM, Stampfli MR, Mossman KL, Ashkar AA. Impairment of human NK cell cytotoxic activity and cytokine release by cigarette smoke. Journal of leukocyte biology. 2008;83(3):774-84.

85. Sorensen LT, Zillmer R, Agren M, Ladelund S, Karlsmark T, Gottrup F. Effect of smoking, abstention, and nicotine patch on epidermal healing and collagenase in skin transudate. Wound Repair Regen. 2009;17(3):347-53.

86. Belibasakis GN, Bostanci N. The RANKL-OPG system in clinical periodontology. Journal of clinical periodontology. 2012;39(3):239-48.

87. Gautam DK, Jindal V, Gupta SC, Tuli A, Kotwal B, Thakur R. Effect of cigarette smoking on the periodontal health status: A comparative, cross sectional study. Journal of Indian Society of Periodontology. 2011;15(4):383-7.

88. An N, Andrukhov O, Tang Y, Falkensammer F, Bantleon HP, Ouyang X, et al. Effect of nicotine and porphyromonas gingivalis lipopolysaccharide on endothelial cells in vitro. PloS one. 2014;9(5):e96942.

89. Genco RJ, Borgnakke WS. Risk factors for periodontal disease. Periodontology 2000. 2013;62(1):59-94.

90. Greene JC, Vermillion JR. The Simplified Oral Hygiene Index. J Am Dent Assoc. 1964;68:7-13.

91. Faul F, Erdfelder E, Lang AG, Buchner A. G*Power 3: a flexible statistical power analysis program for the social, behavioral, and biomedical sciences. Behav Res Methods. 2007;39(2):175-91.

92. Ding L, Xu Y, Liu S, Bi Y, Xu Y. Hemoglobin A1c and diagnosis of diabetes. Journal of diabetes. 2018;10(5):365-72.

93. James EA, Rieck M, Pieper J, Gebe JA, Yue BB, Tatum M, et al. Citrulline-specific Th1 cells are increased in rheumatoid arthritis and their frequency is influenced by disease duration and therapy. Arthritis \& rheumatology. 2014;66(7):1712-22.

94. Stolt P, Bengtsson C, Nordmark B, Lindblad S, Lundberg I, Klareskog L, et al. Quantification of the influence of cigarette smoking on rheumatoid arthritis: results from a population based case-control study, using incident cases. Annals of the rheumatic diseases. 2003;62(9):835-41. 
95. Heliovaara M, Aho K, Aromaa A, Knekt P, Reunanen A. Smoking and risk of rheumatoid arthritis. The Journal of rheumatology. 1993;20(11):1830-5.

96. de Smit MJ, Westra J, Brouwer E, Janssen KM, Vissink A, van Winkelhoff AJ. Periodontitis and Rheumatoid Arthritis: What Do We Know? Journal of periodontology. 2015;86(9):1013-9.

97. Mercado F, Marshall RI, Klestov AC, Bartold PM. Is there a relationship between rheumatoid arthritis and periodontal disease? Journal of clinical periodontology. 2000;27(4):267-72.

98. Che Rahim MJ, Wan Mohamad WM, Saddki N, Taib H, Wan Abhamid WZ, Wong KK, et al. Elevated serum rheumatoid factor, anti-citrullinated protein antibodies and active rheumatoid arthritis disease are not associated with chronic periodontitis. Malays J Pathol. 2019;41(3):267-72.

99. Schmickler J, Rupprecht A, Patschan S, Patschan D, Muller GA, Haak R, et al. CrossSectional Evaluation of Periodontal Status and Microbiologic and Rheumatoid Parameters in a Large Cohort of Patients With Rheumatoid Arthritis. Journal of periodontology. 2017;88(4):368-79.

100. Terao C, Asai K, Hashimoto M, Yamazaki T, Ohmura K, Yamaguchi A, et al. Significant association of periodontal disease with anti-citrullinated peptide antibody in a Japanese healthy population - The Nagahama study. J Autoimmun. 2015;59:85-90.

101. The J, Ebersole JL. Rheumatoid factor (RF) distribution in periodontal disease. J Clin Immunol. 1991;11(3):132-42.

102. Costenbader KH, Feskanich D, Mandl LA, Karlson EW. Smoking intensity, duration, and cessation, and the risk of rheumatoid arthritis in women. Am J Med. 2006;119(6):503 e1-9.

103. Oliver RC, Tervonen T. Diabetes-A Risk Factor for Periodontitis in Adults? Journal of periodontology. 1994;65 Suppl 5S:530-8.

104. Chapple IL, Genco R, working group 2 of the joint EFPAAPw. Diabetes and periodontal diseases: consensus report of the Joint EFP/AAP Workshop on Periodontitis and Systemic Diseases. Journal of periodontology. 2013;84(4 Suppl):S106-12.

105. Jepsen S, Caton JG, Albandar JM, Bissada NF, Bouchard P, Cortellini P, et al. Periodontal manifestations of systemic diseases and developmental and acquired conditions: Consensus report of workgroup 3 of the 2017 World Workshop on the Classification of Periodontal and Peri-Implant Diseases and Conditions. Journal of periodontology. 2018;89 Suppl 1:S237-S48. 
106. Sliwinska-Mosson M, Milnerowicz H. The impact of smoking on the development of diabetes and its complications. Diabetes \& vascular disease research. 2017;14(4):26576.

107. Leite FRM, Nascimento GG, Scheutz F, Lopez R. Effect of Smoking on Periodontitis: A Systematic Review and Meta-regression. Am J Prev Med. 2018;54(6):831-41.

108. Tarnowski M, Duda-Sobczak A, Lipski J, Zozulinska-Ziolkiewicz D, WyganowskaSwiatkowska M. Tobacco smoking decreases clinical symptoms of gingivitis in patients with type 1 diabetes-a cross-sectional study. Oral diseases. 2018;24(7):1336-42.

109. Baeza M, Morales A, Cisterna C, Cavalla F, Jara G, Isamitt Y, et al. Effect of periodontal treatment in patients with periodontitis and diabetes: systematic review and meta-analysis. J Appl Oral Sci. 2020;28:e20190248.

110. Huang J, Xiao Y, Xu A, Zhou Z. Neutrophils in type 1 diabetes. J Diabetes Investig. 2016;7(5):652-63.

111. Tervonen T, Karjalainen K. Periodontal disease related to diabetic status. A pilot study of the response to periodontal therapy in type 1 diabetes. Journal of clinical periodontology. 1997;24(7):505-10.

112. Muller F, Naharro M, Carlsson GE. What are the prevalence and incidence of tooth loss in the adult and elderly population in Europe? Clinical oral implants research. 2007;18 Suppl 3:2-14.

113. Musacchio E, Perissinotto E, Binotto P, Sartori L, Silva-Netto F, Zambon S, et al. Tooth loss in the elderly and its association with nutritional status, socio-economic and lifestyle factors. Acta odontologica Scandinavica. 2007;65(2):78-86.

114. Taylor JJ, Preshaw PM, Lalla E. A review of the evidence for pathogenic mechanisms that may link periodontitis and diabetes. Journal of clinical periodontology. 2013;40 Suppl 14:S113-34.

115. Quintero AJ, Chaparro A, Quirynen M, Ramirez V, Prieto D, Morales H, et al. Effect of two periodontal treatment modalities in patients with uncontrolled type 2 diabetes mellitus: A randomized clinical trial. Journal of clinical periodontology. 2018;45(9):1098-106.

116. WHO Guidelines Approved by the Guidelines Review Committee. Use of Glycated Haemoglobin (HbA1c) in the Diagnosis of Diabetes Mellitus: Abbreviated Report of a WHO Consultation. Geneva: World Health Organization; 2011. 
117. Gupta N, Gupta ND, Garg S, Goyal L, Gupta A, Khan S, et al. The effect of type 2 diabetes mellitus and smoking on periodontal parameters and salivary matrix metalloproteinase-8 levels. Journal of oral science. 2016;58(1):1-6.

118. Orbak R, Tezel A, Canakci V, Demir T. The influence of smoking and non-insulindependent diabetes mellitus on periodontal disease. J Int Med Res. 2002;30(2):116-25.

119. Javed F, Al-Kheraif AA, Salazar-Lazo K, Yanez-Fontenla V, Aldosary KM, Alshehri M, et al. Periodontal Inflammatory Conditions Among Smokers and Never-Smokers With and Without Type 2 Diabetes Mellitus. Journal of periodontology. 2015;86(7):839-46.

120. Miranda TS, Almeida ML, Marins LM, da Silva HDP, Feres M, Duarte PM. Might smoking assuage the pro-inflammatory effect of diabetes in periodontal sites? Oral diseases. 2020;26(1):200-12. 


\section{Acknowledgment}

First of all, I wish to thank Dr. habil. Márk Antal, for his constant help, support and supervision.

I would also thank Dr. habil. Zoltán Baráth, dean of the Faculty of Dentistry for his support and encouragement.

It is with immense gratitude that I acknowledge the support and help of Dr. Gábor Braunitzer with the publications and the statistical analysis.

I would also like to express my gratitude to Dr. Krisztina Timár for her language editing and translational efforts.

A hearty thank you goes out to my co-authors, Professor Csaba Lengyel, Professor Tamás Várkonyi, Dr. habil. László Kovács, Dr. Márta Bocskai and Dr. Szabolcs Nyiraty.

It gives me great pleasure to acknowledge the help of Dr. Gabriella Eördegh for her ideas and appreciation, beside her wisdom and assistance.

I would also like to thank my collegues at the Department of Operative and Esthetic dentistry. Finally, this thesis would not have been possible without the support and love of my family. 
X. Publications 
I. 


\title{
Periodontal Disease in Diabetes Mellitus: A Case- Control Study in Smokers and Non-Smokers
}

\author{
Emese Battancs · Dorottya Gheorghita $\cdot$ Szabolcs Nyiraty \\ Csaba Lengyel · Gabriella Eördegh · Zoltán Baráth • Tamás Várkonyi • \\ Márk Antal (D)
}

Received: July 11, 2020 / Accepted: September 15, 2020

(C) The Author(s) 2020

\begin{abstract}
Introduction: It is well established that periodontal disease (PD) and diabetes mellitus (DM) can have a detrimental effect on each other's disease course, and that cigarette smoking exacerbates both conditions. However, literature on the periodontal status of smokers with DM is scarce, and the studies conducted to date did not use healthy controls or non-smokers with DM as controls. Consequently, the individual effects of smoking and DM on PD are difficult to untangle and estimate.
\end{abstract}

Methods: A total of 128 participants were recruited to this study and their data analyzed. They were assigned to four groups: smoking

E. Battancs · D. Gheorghita $\cdot$ M. Antal $(\bowtie)$ Department of Esthetic and Operative Dentistry, Faculty of Dentistry, University of Szeged, Szeged, Hungary

e-mail: antal.mark@szte.hu

S. Nyiraty · C. Lengyel · T. Várkonyi

Department of Internal Medicine, Faculty of

Medicine, University of Szeged, Szeged, Hungary

G. Eördegh

Faculty of Health Sciences and Social Studies,

University of Szeged, Szeged, Hungary

Z. Baráth

Department of Prosthodontics, Faculty of Dentistry,

University of Szeged, Szeged, Hungary patients with DM (SDM); non-smoking patients with DM (NSDM); smokers without DM (control group, SC) and (4) non-smokers without DM (control group, NSC). Each group consisted of 32 age-matched participants. The periodontal status of the participants was assessed by full oral examination. To express periodontal status, we used the four-stage classification introduced by Fernandes and colleagues (J Periodontol. 80(7):1062-1068, 2009). The control of DM was estimated by measuring hemoglobin A1c (HbA1c) levels in the peripheral blood.

Results: A significant difference in the severity of PD was found between the SC and NSC groups $(p=0.027)$ and between the NSC and SDM groups $(p=0.000)$, while the difference between the NSDM and SDM groups approached significance $(p=0.052)$. No person in the smoker groups could be classified as having a healthy periodontal status. The four-stage classification followed a normal distribution in the healthy, non-smoking controls (NSC). Smoking caused a shift toward medium-severe PD, while a marked shift toward the most severe stage was observed when both smoking and DM were present (SDM). There was no significant association between the type of DM and periodontal status, nor between diabetes control and the severity of PD. Persons in the SDM group had significantly fewer teeth than those in the NSC group (mean \pm standard deviation: $16.0 \pm 7.9$ vs. $20.7 \pm 5.6 ; p=0.02)$. 
Conclusion: Smoking damages the periodontium of even healthy individuals, but the damage is multiplied in a smoker who has DM, even though the effect of DM alone on periodontium health is relatively mild. Our results suggest a synergy between DM and smoking in terms of damage to the periodontal tissues, but the limited sample size of this study does not allow any hard conclusion to be drawn.

Keywords: Comorbidity; Inflammation; Periodontal diseases; Smoking; Type 1 diabetes mellitus; Type 2 diabetes mellitus

\section{Key Summary Points}

Why carry out this study?

Periodontal disease (PD) and diabetes mellitus (DM) are known to detrimentally affect each other's disease course, and cigarette smoking independently exacerbates both conditions.

Existing literature on the periodontal status of patients with DM who smoke is scarce, and studies conducted to date did not use healthy controls or non-smoking patients with DM as controls; consequently, the individual effects of smoking and DM on PD are difficult to estimate.

We hypothesized that the periodontal status of patients with DM with no smoking history would be significantly poorer than that of healthy non-smoking controls, and that periodontal status in the former would be further exacerbated by smoking.

\section{What was learned from the study?}

The periodontal status of 128 participants categorized into four groups, namely smoking patients with DM (SDM), nonsmoking patients with DM (NSDM), (3) smokers without DM (control group, SC) and non-smokers without DM (control group, NSC), was assessed.
A significant difference in severity of $\mathrm{PD}$ was found between the SC and NSC $(p=0.027)$ groups and between the NSC and SDM $(p=0.000)$ groups, while the difference between the NSDM and SDM groups was nearly significant $(p=0.052)$. In the smoker groups, no one could be classified as having a healthy periodontal status.

In this study, smoking caused a shift toward medium-severe PD, while a marked shift toward the most severe stage was observed when smoking was combined with DM.

\section{DIGITAL FEATURES}

To view digital features for this article go to https://doi.org/10.6084/m9.figshare.12957311.

\section{INTRODUCTION}

Studies have established that periodontal status and systemic diseases have an effect on each other [1]. The most studied interactions are those between periodontal disease (PD) and cardiovascular conditions [2], rheumatoid arthritis [3-5] and diabetes [6-8], but relationships between PD and hypertension [8], osteoporosis [9], psoriasis [10, 11] pulmonary diseases [12], pregnancy and perinatal complications [13-15] have also been shown.

$\mathrm{PD}$ is a chronic, destructive oral condition characterized by infection-related inflammation of the tooth-supporting tissues, leading to bone destruction and tooth loss [16]. Excessive inflammation of the periodontal tissues (periodontitis) is the hallmark feature of PD. In PD, bacteria in the oral biofilm interfere with the body's defense mechanisms, activating the immune system which in turn results in inflammation and the immune response $[17,18]$. The levels of C-reactive protein, prostaglandin $\mathrm{E}_{2}$ interleukin-1beta, and tumor 
necrosis factor alpha increase in PD [19]. A similar increase in the presence and concentration of these inflammatory mediators has also been observed in persons with diabetes mellitus (DM) $[20,21]$.

In type 1 diabetes (T1D), the pancreas is unable to produce (enough) insulin, whereas type 2 diabetes (T2D) is characterized by insulin resistance often combined with a relatively low level of insulin secretion. According to the World Health Organization, the prevalence of DM worldwide in 2014 was $8.5 \%$ [22]. DM has several known complications, including retinopathy, nephropathy, neuropathy, macrovascular abnormalities, prolonged wound healing and PD [23]. The increasing number of recent studies that have focused on examining the relationship between DM and PD testified to a definite surge in scientific interest [24-26]. Given that certain cytokines and other inflammatory mediators are involved in both diseases, DM and PD appear to have a mutually detrimental effect on each other. A strong correlation was found between PD and DM [27-29], as well as between PD and the metabolic control of DM both in T1D and T2D [30-36]. According to some authors, this relationship is two-way [37-39], which has led to the notion that periodontal therapy may influence DM outcomes $[40,41]$. In support of this, a positive effect of periodontal therapy on DM outcomes has been observed in various studies [41-44].

Smoking is a harmful and addictive habit which, in addition to being an addiction, gives rise to or exacerbates various pathological conditions [45-48], including DM and PD. Obradovic and co-workers studied smokers and nonsmokers with T1D or T2D who also had PD and found that smoking had an adverse effect on the periodontal status of these patients. An obvious weakness of that study was that only patients with PD were enrolled in the study and, consequently, no comparison was made with healthy controls [49]. Gupta and colleagues investigated the relationship between T2D and smoking in patients with PD and observed that the periodontal status of these patients with PD was significantly worse in the group of smokers with DM than in the group of non-smokers with T2D [50]. Obrak and co-workers found that the periodontal status of non-smokers with T2D with and PD was better than that of their smoking counterparts [51], while Javed and coworkers found that both DM and smoking had a detrimental effect on the periodontal status of patients [52]. These studies draw a hypothetical picture in which DM damages the integrity of the periodontium and smoking likely boosts this effect. Unfortunately, none of these aforementioned studies used healthy controls, so their results cannot be regarded as strong evidence supporting the hypothesis they set up to test. It should also be noted that the relationship between smoking and periodontal status has not yet been investigated and compared to healthy controls in patients with T1D or T2D who have good periodontal health. The aim of this study was to fill the gaps in the literature by examining the relationship between smoking and periodontal status in both patients with DM (T1D or T2D) and healthy controls.

Our research group has been investigating the relationship between various systemic diseases for a decade, including systemic conditions such as psoriasis and rheumatoid arthritis, and we are especially interested in the additional effect of smoking [25]. In 2014, we first proposed that smoking may act as a permissive factor of PD in patients with psoriasis [11], and we subsequently demonstrated something similar in rheumatoid arthritis [53]. In the exploratory study reported here, we hypothesized that (1) the periodontal status of patients with DM with no smoking history would be significantly poorer than that of healthy nonsmoking controls, and (2) this effect would be exacerbated by smoking. The specific question we sought an answer to was whether PD occurs more often and in a more serious form in smokers with DM than in non-smokers with $\mathrm{DM}$. Thus, the aim of the this study was to find evidence for or against the permissive/boosting effect of smoking on periodontal destruction in patients with DM. The effect of various subfactors (such as the type of DM and the success of blood glucose control) was also considered. 
Table 1 Descriptive statistics of the patient and control groups

\begin{tabular}{|c|c|c|}
\hline Descriptive statistic of the patient and control groups & Diabetes patient groups & Control groups \\
\hline \multicolumn{3}{|l|}{ Age (years) } \\
\hline Smoker subsample & $54.5 \pm 13.4$ & $54.0 \pm 13.6$ \\
\hline Non-smoker subsample & $54.3 \pm 13.9$ & $54.5 \pm 13.9$ \\
\hline \multicolumn{3}{|l|}{ Sex ratio } \\
\hline Non-smoker subsample & 18F:14 M (56\%:44\%) & 20F:12 M (62\%:38\%) \\
\hline Smoker subsample & 18F:14 M (56\%:44\%) & 22F:10 M (69\%:31\%) \\
\hline \multicolumn{3}{|l|}{$\mathrm{CAL}(\mathrm{mm})$} \\
\hline Smoker subsample & $2.94 \pm 1.60$ & $2.51 \pm 1.32$ \\
\hline Non-smoker subsample & $2.83 \pm 1.51$ & $2.50 \pm 1.24$ \\
\hline \multicolumn{3}{|l|}{$\mathrm{PPD}(\mathrm{mm})$} \\
\hline Smoker subsample & $2.60 \pm 1.25$ & $2.27 \pm 1.06$ \\
\hline Non-smoker subsample & $2.71 \pm 1.28$ & $2.30 \pm 0.98$ \\
\hline \multicolumn{3}{|l|}{ Number of teeth } \\
\hline Smoker subsample & $16 \pm 8.0$ & $19.2 \pm 7.5$ \\
\hline Non-smoker subsample & $18 \pm 7.9$ & $20.7 \pm 5.7$ \\
\hline T1D subsample & $22 \pm 6.5$ & NA \\
\hline T2D subsample & $16.2 \pm 7.7$ & NA \\
\hline
\end{tabular}

Values in table are presented as the mean \pm standard deviation (SD) or as frequencies (number of observations with the percentage in parenthesis)

$C A L$ Clinical attachment level (distance between the cemento-enamel junction and the bottom of the pocket), $F$ female, $M$ male, $P P D$ probing pocket depth (distance between the marginal gingiva and the bottom of the periodontal pocket), T1D/ $T 2 D$ type 1 type 2 diabetes

\section{METHODS}

\section{Patients}

Patients with DM were recruited form the Department of Internal Medicine of the University of Szeged, Faculty of Medicine, Szeged, Hungary, and healthy controls were recruited from the Csongrád County Pulmonary Screening Station, Szeged, Hungary in 2018-2019. Before enrollment, all participants had been informed about the study. Participation was voluntary, and written informed consent was obtained from each participant. The protocol of the study conformed in all respects to the tenets of the Declaration of Helsinki of
1964, and its later amendments, and the study was approved by the Regional Research Ethics Committee for Medical Research at the University of Szeged, Hungary (144/2014-B/001, accepted 2014, modified in 2019).

A total of 128 participants were enrolled in the study. These participants were assigned to four groups: (1) smoking patients with DM (SDM); (2) non-smoking patients with DM (NSDM); (3) smokers without DM (control group, SC) and (4) non-smokers without DM (control group, NSC). Each group consisted of 32, age-matched participants. Gender matching was also possible in most cases, but females were over-represented in both the patient and the control groups. Detailed descriptions of the 
Table 2 Disease duration, complications and co-morbidities among patients with diabetes

\begin{tabular}{|c|c|c|}
\hline $\begin{array}{l}\text { Disease duration, } \\
\text { complications and co- } \\
\text { morbidities }\end{array}$ & $\begin{array}{l}\text { Smokers } \\
\text { with } \\
\text { diabetes }\end{array}$ & $\begin{array}{l}\text { Non-smokers } \\
\text { with diabetes }\end{array}$ \\
\hline Duration of disease (years) & $\begin{array}{l}18.56 \\
\quad \pm 7.8\end{array}$ & $\begin{array}{l}18.72 \\
\quad \pm 10.03\end{array}$ \\
\hline T1D & $10(31.3 \%)$ & $12(37.5 \%)$ \\
\hline $\mathrm{T} 2 \mathrm{D}$ & $22(68.8 \%)$ & $20(62.5 \%)$ \\
\hline Diabetic nephropathy & $8(25 \%)$ & $11(34.4 \%)$ \\
\hline Diabetic retinopathy & $3(9.4 \%)$ & $12(37.5 \%)$ \\
\hline Diabetic polyneuropathy & $10(31.3 \%)$ & $15(46.9 \%)$ \\
\hline $\begin{array}{l}\text { Chronic obstructive } \\
\text { pulmonary disease }\end{array}$ & $2(6.3 \%)$ & $3(9.4 \%)$ \\
\hline Asthma & $2(6.3 \%)$ & $2(6.3 \%)$ \\
\hline
\end{tabular}

Values in table are presented as the mean $\pm S D$ or as frequencies (number of observations with the percentage in parenthesis)

group characteristics are given in Tables 1 and 2 . Patients with T1D or T2D were included in the study. Participants in the control group were free of any systemic disease. Patients in the DM groups were compared to age- and gender-matched controls.

The exclusion criteria for all groups were determined based on relevant literature and included obesity (body mass index $\geq 30 \mathrm{~kg} / \mathrm{m}^{2}$ ), excessive alcohol consumption, drug abuse, rheumatoid arthritis and diseases causing neutropenia and local or systemic inflammatory conditions (other than DM) [54]. Poor oral hygiene, defined as a Simplified Oral Health Index (OHI-S) score $>3$ [55] was also an exclusion criterion. Pregnant women, patients receiving cancer therapy, toothless patients or patients with $<3$ teeth, patients with a serum creatinine level $\geq 1.6 \mathrm{mg} / \mathrm{dL}$ and patients with hemoglobinopathy or any other type of hemorrhagic disorder were excluded from the study. Patients in need of antibiotic prophylaxis for any reason or who had received antibiotics within 2 weeks prior to study initiation were also excluded, as were individuals wearing orthodontic braces. Demographic and tobacco use data were collected by means of a questionnaire. A smoker was defined as a person who reported smoking at least two cigarettes for an uninterrupted period of 1 year prior to study initiation. A non-smoker was defined as a person with no self-reported tobacco use for 30 years prior to study initiation. Former smokers were not included in the sample as the category is rather vague (especially when talking about self-reported tobacco use); in addition, the relatively limited sample size would not have allowed a meaningful analysis of an additional category. Smokers in both patient and control groups were comparable in terms of smoking history expressed in pack-years (mean \pm standard deviation [SD] pack-years: patients $17.19 \pm 15.81$, controls $16.47 \pm 13.70$ ). Medical information on both controls and patients with DM was extracted from patient files and hospital records.

The required sample size was calculated with $G^{*}$ Power version 3.1. 5. (University of Kiel, Kiel, Germany), a software program designed especially for statistical power and sample size computation [56]. The software allows the computation of achieved statistical power (posthoc) and required sample size (a priori). As mostly categorical variables were to be analyzed, a priori sample size estimation was performed for crosstabs/chi square/contingency tables, with the following input parameters: effect size $(w): 0.3 ; \alpha$ : 0.05 ; power $(1-\beta)$ : 0.82 ; $d f: 3$. Required sample size was calculated to be $n=128$ (for four groups: DM smoker/DM nonsmoker; control smoker/control non-smoker). It should be noted that the study was powered for the hypothesis tests defined in the section "Statistical Analysis"; more complicated analyses (e.g. regression analyses with multiple predictor variables) were not possible with this sample size. Consequently, this study must be regarded as exploratory in nature.

\section{Parameters Studied}

Control of diabetes was estimated by measuring hemoglobin A1c (HbA1c) levels in the 
Table 3 Severity of periodontal disease by study group

\begin{tabular}{llcrr}
\hline Study groups $^{\mathbf{a}}$ & \multicolumn{4}{l}{ Fernandes et al. classification of PD [16] } \\
\cline { 2 - 5 } & Healthy periodontal status & Early PD & Moderate PD & Severe PD \\
\hline NSC & $4(12 \%)$ & $11(34 \%)$ & $12(37 \%)$ & $5(16 \%)$ \\
SC & $0(0.0 \%)$ & $3(9 \%)$ & $19(59 \%)$ & $10(31 \%)$ \\
NSDM & $2(6 \%)$ & $2(6 \%)$ & $19(59 \%)$ & $9(28 \%)$ \\
SDM & $0(0 \%)$ & $1(3 \%)$ & $11(34 \%)$ & $20(63 \%)$ \\
\hline
\end{tabular}

Values in table are presented as the frequency (number with percentage in parentheses)

$P D$ Periodontal disease

a Study groups categorized by periodontal disease: SDM, smoking patients with DM; NSDM, non-smoking patients with DM; SC, smokers without DM (control group); NSC, non-smokers without DM (control group)

peripheral blood [57]. Diabetes was considered to be well controlled at HbA1c $\leq 7 \%$, moderately controlled at HbA1c $>7.01$ and $\leq 8.5 \%$ and poorly controlled at $\mathrm{HbA} 1 \mathrm{c}>8.5 \%$.

The periodontal status of the patients was assessed by full oral examination, where probing pocket depth (PPD; distance between the marginal gingiva and the bottom of the periodontal pocket, in millimeters), bleeding on probing (BOP; bleeding that is induced by gentle manipulation of the tissue at the depth of the gingival sulcus with a periodontal probe), clinical attachment loss (CAL; distance between the cemento-enamel junction and the bottom of the pocket, in millimeters) and the amount of plaque were evaluated. PPD, BOP, CAL and the amount of plaque was measured at six locations per tooth (mesiobuccally, buccally, distobuccally, distolingually, lingually and mesiolingually), with the exception of the wisdom teeth (which were not evaluated in this study). Williams probes (Hu-Friedy Manufacturing Co. Chicago, IL, USA) were used [58]. Assessment of the clinical severity of PD is still a matter of debate, and several assessment methods are described in the literature for various purposes, from clinical use to epidemiological work [59]. In this study, we used the classification introduced by Fernandes et al. [16]: (1) the participant is considered to have a healthy periodontal status if no CAL or BOP can be detected; (2) early PD is defined as CAL $\geq 1 \mathrm{~mm}$ at $\geq 2$ teeth; (3) moderate PD is defined as CAL $\geq 4 \mathrm{~mm}$ at 3 locations and $\mathrm{PPD} \geq 3 \mathrm{~mm}$ in at least 2 locations; (4) severe PD is defined as CAL $\geq 6 \mathrm{~mm}$ at $\geq 2$ teeth and PPD $\geq 5 \mathrm{~mm}$ at $\geq$ 1 location. To characterize the groups in more detail, we calculated and recorded PPD and CAL separately for each participant, as recommended in other studies $[60,61]$.

\section{Statistical Analysis}

Statistical analyses were performed in SPSS version 21.0 statistical software (IBM Corp., Armonk, NY, USA). Continuous variables were described as means $\pm S D$, and categorical variables were characterized as frequencies. For hypothesis testing, one-way analysis of variance (ANOVA; with Tukey's post-hoc test) or Kruskal-Wallis ANOVA (with Mann-Whitney $U$ tests for the pairwise comparisons) were used, depending on whether the normality and homogeneity assumptions were fulfilled. To test the association between categorical variables, we used the chi-square test. If a significant association was found, the dataset was further analyzed with Kruskal-Wallis ANOVA (with Mann-Whitney $U$ tests for the pairwise comparisons). The general limit of significance was set at $p=0.05$, but it was corrected for multiple comparisons with the Bonferroni correction where necessary. 

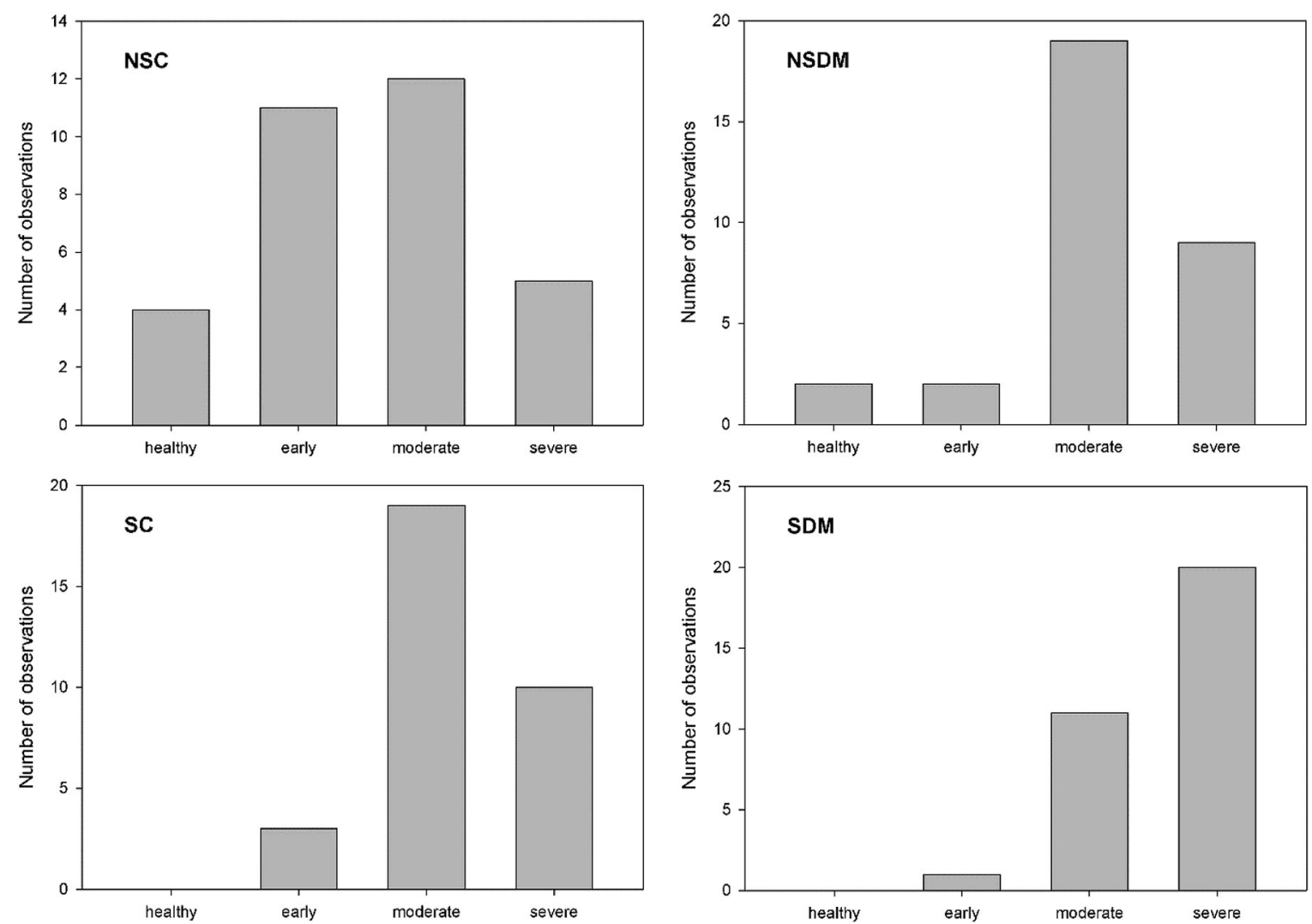

Fig. 1 Distribution of severity stages of periodontal disease across groups (Fernandes et al. classification of PD [16]). Note that while the severity stages follow a normal distribution in healthy, non-smoking controls, smoking causes a definite shift to the right, and when smoking is

combined with diabetes, an extreme shift to the right can be observed. SDM Smoking patients with DM, NSDM non-smoking patients with DM, $S C$ smokers without DM (control group), NSC non-smokers without DM (control group)

Table 4 Severity of periodontal disease by glycemic control as assessed by hemoglobin A1c status

\begin{tabular}{lllll}
\hline HbA1c status $^{\mathbf{a}}$ & Healthy periodontal status & Early PD & Moderate PD & Severe PD \\
\hline WC & $1(6.3 \%)$ & $0(0.0 \%)$ & $9(56.3 \%)$ & $6(37.5 \%)$ \\
MC & $01(4.0 \%)$ & $2(8.0 \%)$ & $12(48.0 \%)$ & $10(40.0 \%)$ \\
PC & $0(0.0 \%)$ & $1(4.3 \%)$ & $9(39.1 \%)$ & $13(56.5 \%)$ \\
\hline
\end{tabular}

Values in table are presented as the frequency (number with percentage in parentheses)

${ }^{a}$ Hemoglobin Alc (HbAlc) status: WC (well-controlled): HbAlc $\leq 7 \%$; MC (moderately controlled): HbAlc $>$ $7.01 \%, \leq 8.5 \%$; PC (poorly controlled): HbAlc $>8.5 \%$

\section{RESULTS}

\section{Periodontal Status by Group}

Group membership was significantly associated with the severity of PD $\left(\chi^{2}=36.910, p=0.000\right.$; see also Table 3). Subsequent analysis of the data using Kruskal-Wallis ANOVA revealed significant variance across the four groups in terms of severity of $\mathrm{PD}(H(3)=25.659, p=0.000)$. The pairwise comparisons showed a significant difference in severity of PD between the SC and 
NSC groups $(p=0.027)$ and between the NSC and SDM groups $(p=0.000)$; the difference between the NSDM and SDM groups was nearly significant $(p=0.052)$. Of note is that no one in the two smoker groups was classified as having good periodontal health. As shown in Table 3, the significant between-group differences most probably were due to differences in the frequency of the severe stage of PD across the groups, with the lowest frequency of severe PD found among those in the NSC group (15.6\%), followed in increasing order of frequency among those in the NSDM group (28.1\%) and SC group (31.3\%), peaking in the SDM group $(62.5 \%)$. The other stages of PD did not show such notable between-group differences (apart from the already mentioned healthy stage, but the frequency of this stage was quite low in all groups). It is remarkable that while the stages of PD followed a normal distribution in the healthy, non-smoking controls, smoking seemed to cause a shift toward the middle of the severity spectrum, and when smoking was combined with DM, a marked shift toward the most severe stage was observed (Fig. 1).

\section{Diabetes Type, Glycemic Control and Periodontal Status}

There was no significant association between the type of diabetes (T1D or T2D) and periodontal status $\left(\chi^{2}=6.190, p=0.103\right)$, and the distribution of the four stages of periodontal status was almost the same in these two diabetic subgroups, with the exception that severe PD was $17.5 \%$ more frequent in the T2D subgroup than in the T1D subgroup. However, T2D was over-represented in the study sample $\left(n_{\text {type2- }}\right.$ $=42$ vs. $n_{\text {type } 1}=22$ ), so the validity of this observation cannot be established with safety. There was also no significant association between diabetes control and the severity of PD $\left(\chi^{2}=15.503, p=0.078\right)$, but the results of the analysis suggest that the frequency of the severe stage increased with the worsening of diabetes control $\quad\left(n_{\text {well }} \quad\right.$ controlled $=6 ; \quad n_{\text {moderate }}=10$; $n_{\text {mpoorly controlled }}=13$; see Table 4 ).

\section{Number of Teeth}

Pairwise comparisons (Tukey's HSD [honestly significant difference] test) indicated that patients in the SDM group had significantly fewer teeth (mean \pm SD: $16.0 \pm 7.9$ ) than subjects in the NSC group $(20.7 \pm 5.6)$ at $p=0.02$. No other comparison returned a significant result. There was stepwise difference in the mean number of teeth between groups, with patients in the SDM group having the lowest mean number of teeth and subjects in the NSC group having the highest (see also Table 1). In terms of the number of teeth by DM type, patients with T1D had significantly more teeth than patients with T2D $(22 \pm 6.5$ vs. $16.2 \pm 7.7$; $p=0.01)$.

\section{DISCUSSION}

It is well established in the literature that smoking is a major risk factor for developing and aggravating DM and its complications. This is especially true for $\mathrm{T} 2 \mathrm{D}$, the most common form of DM worldwide [62, 63]. It is also known that PD is a frequent sequela of diabetes, so much so that Harald Löe termed it "the sixth complication of diabetes mellitus" [23]. In this study we sougth to answer the question "what effect does smoking have on this specific complication" by analyzing the periodontal status of both smoking and non-smoking patients with DM.

The results are clear in the sense that that while periodontal status followed a normal distribution in healthy, non-smoking controls, smoking caused a shift toward the middle of the PD spectrum, and when smoking was combined with diabetes, a marked shift toward the most severe stage was seen. This result was expected, as it is known that smoking damages the periodontal tissues even in otherwise healthy persons and has a detrimental effect on the progression of PD [64]. We considered it therefore safe to hypothesize that smoking would turn out to be even more detrimental when the primary disease, itself known to have the ability to initiate (and probably aggravate) PD, is present. Within the limits of the present study, we 
believe we have verified this hypothesis. However, the data gathered in this study do not allow an explanation of how exactly DM and smoking interact to aggravate PD. As such, the results may be interpreted as evidence to support the existence of such a detrimental interaction.

We also hypothesized that the periodontal status of diabetic patients with no smoking history would be significantly poorer than that of healthy non-smoking controls. We believed that this hypothesis was logical based on the established relationship between DM and PD. However, it would appear that the results of our study fail to bear this out; for example, there was no remarkable difference between the NSC and NSDM groups (except for the early stage, but not in general). We do not believe that these results should be interpreted as evidence against the well-established relationship; rather, the explanation most likely lies in technical factors and is related to the method of assessment and the different ways in which DM and smoking exert their detrimental effect on the periodontium. Smoking, in fact, can be regarded as repeated episodes of an aggressive chemical attack against the tissues. Smoking damages the periodontal tissues in both systemic and local ways [64], with smoking-induced periodontal inflammation always being the more severe type. Diabetes, on the other hand, develops over a course of time and seems to exert its effects on periodontal tissues effects more slowly and in finer, less direct ways. To give just one expressive example, the antibacterial capacity of the saliva can be downregulated in persons with DM over time, which favors the growth of periodontopathogenic bacterial species [65]. The end result is that while smoking has a rapid effect on the periodontium and maintains a high level of severe inflammation through repeated exposure of these tissues to toxic chemicals, severe stages of periodontal inflammation in DM develop later in the course of the disease and the inflammation is milder than that induced by smoking. As the classification we used measures the actual severity of the periodontal inflammatory process, it is not surprising that it cannot show the fine DM-related difference as efficiently as the massive difference caused by smoking. Still, it should be noted that the classification does not fail to capture the effect of DM entirely: our results clearly show that when smoking is paired up with DM, the destruction of the periodontium is significantly more severe. In summary, DM has a damaging effect on the periodontium, but the clinical staging we used to assess the severity of the inflammation is less sensitive to the effects of DM. While this might be regarded as a weakness of the study, in our professional opinion the classification of Fernandes and colleagues [16] is still the best available classification for study purposes, as it is easy to use and interpret and has a strong positive correspondence to the histopathology of PD.

In terms of the effect of diabetes type, our results suggest that $\mathrm{T} 2 \mathrm{D}$ may be more damaging to the periodontium than T1D, as reflected by the mean number of teeth and the relatively higher prevalence of the most severe stage in participants with T2D. However, the sample size was not large enough for us to allow firm conclusions and, in addition, T2D was over-represented (which is realistic but not optimal for the comparison of the two types). As for the lower number of teeth in patients with T2D, it cannot be excluded that the observed tooth loss is the result of lifestyle rather than the DM itself, given that an unhealthy diet is a major risk factor for the development of T2D [66]. We suggest that this is an interesting finding which may be worth pursuing in future studies, but our results are not sufficient to discuss this topic in any detail.

Glycemic control is another factor which was found not to significantly influence the severity of PD (or vice versa), although the descriptive statistics clearly show that glycemic control became poorer with increasingly severe stage of PD. Taken together, it would appear that there is an effect of glycemic control on PD (in either direction), but that this effect is either statistically non-significant or significant but with too small an effect size to show significance in this sample size. The literature is divided over this question but leans more toward the no-effect side. A number of earlier studies with sample sizes similar to our sample size, 
such as the study of Fernandes and colleagues [16], have also failed to show a significant association between PD severity and glycemic control. In their review, Taylor and colleagues also concluded that there is no such connection [67]. However, there are also studies supporting the counter-argument, providing strong evidence that HbA1c improved as a result of periodontal treatment [43, 68]. A possible explanation for the obvious uncertainty of thes results is that while HbA1c is a well-established clinical parameter that helps treatment, it primarily allows the assessment of the risk of microvascular complications [69]. While microvascular factors may contribute to the deterioration of periodontal status in DM, PD is still predominantly a disease of immunological/ microbiological origin. In short, while our results seem to support the existence of a weak connection, HbA1c might not be the best parameter to link DM with PD. It is safe to assume that results from continuous glucose monitoring would allow a much more decisive conclusion, but we did not have that option. This is definitely a limitation to our study, but in Hungary, continuous monitoring is not widespread and, consequently, collecting data on even the relatively small number of patients with regularly recorded continuous monitoring data was extremely difficult. In contrast, HbA1c is routinely and meticulously recorded for all patients receiving diabetes care. We had to choose between reporting the routinely recorded standard parameter or omitting glycemic control altogether, and the latter did not appear to be the adequate choice in the given context.

As often happens, our study has resulted in more questions than it can answer, but we believe that we can draw at least one valid conclusion: smoking damages even the healthy periodontium, but when a DM patient smokes, the destruction multiplies. This is quite similar to what our research group described about the relationship between smoking and PD in psoriasis [11]. In that study, we concluded that smoking and psoriasis act in synergy to boost periodontal inflammation, which in turn leads to the over-representation of the most severe stage in smoking patients. The situation appears to be the same in the case of diabetes, i.e. the relatively mild damaging effect of the disease itself is multiplied by the repeated chemical challenge of cigarette smoke exposure. How this effect is realized goes beyond the scope of this study, but it is safe to assume that the process has both microvascular and immunological components, and it is probably the meeting of these different pathogenic pathways that gives rise to the observed massive deterioration. Some studies have addressed the issue of the effect of smoking and DM on periodontal health [50-52], but none of these concentrated explicitly on the interaction of the two factors. Our results are new in this respect and demonstrate another way in which smoking can do further damage to the health of patients with DM.

\section{CONCLUSIONS}

Within the limitations of this study, we conclude that smoking damages even the healthy periodontium, but when a DM patient smokes, the destruction caused by smoking is multiplied, while the effect of DM alone is relatively mild. These results might be interpreted as indicative of a synergy between DM and smoking to damage the periodontal tissues, but standing alone they do not allow us to draw a hard conclusion, especially as the size of the study sample did not allow more in-depth analyses. The details thus remain to be clarified. Nevertheless, based on these results, we conclude that the increased risk of severe PD is another reason why patients with DM should be discouraged from smoking.

\section{ACKNOWLEDGEMENTS}

The authors would like to express their gratitude to Dr. Gábor Braunitzer for his critical comments on the manuscript. We would like to thank the participants of the study for their time and cooperation. 
Funding. No funding was received for this research. The Rapid Service Fee was funded by the OA funding of the University of Szeged.

Authorship. All named authors meet the International Committee of Medical Journal Editors (ICMJE) criteria for authorship for this article, take responsibility for the integrity of the work as a whole, and have given their approval for this version to be published.

Authorship Contributions. MA designed the research and coordinated the research team; EB, DG and $\mathrm{SN}$ performed patient evaluation and collected patient data; CL, GE, ZB and TV analyzed the data and drafted the manuscript; EB, DG and MA wrote and made the final version of the manuscript. All authors have read and approved the final manuscript.

Disclosures. Emese Battancs, Dorottya Gheorghita, Szabolcs Nyiraty, Csaba Lengyel, Gabriella Eördegh, Zoltán Baráth, Tamás Várkonyi and Márk Antal have nothing to disclose.

Compliance with Ethics Guidelines. Participation was voluntary, and written informed consent was obtained from each participant. The protocol and design of the study conformed in all respects to the tenets of the Declaration of Helsinki of 1964, and its later amendments, and the study was approved by the Regional Research Ethics Committee for Medical Research at the University of Szeged, Hungary (144/2014-B/001, accepted 2014, modified in 2019).

Data Availability. The datasets generated during and/or analyzed during the current study are available from the corresponding author on reasonable request.

Open Access. This article is licensed under a Creative Commons Attribution-NonCommercial 4.0 International License, which permits any non-commercial use, sharing, adaptation, distribution and reproduction in any medium or format, as long as you give appropriate credit to the original author(s) and the source, provide a link to the Creative Commons licence, and indicate if changes were made. The images or other third party material in this article are included in the article's Creative Commons licence, unless indicated otherwise in a credit line to the material. If material is not included in the article's Creative Commons licence and your intended use is not permitted by statutory regulation or exceeds the permitted use, you will need to obtain permission directly from the copyright holder. To view a copy of this licence, visit http://creativecommons.org/licenses/by$\mathrm{nc} / 4.0 /$.

\section{REFERENCES}

1. Molloy J, Wolff LF, Lopez-Guzman A, Hodges JS. The association of periodontal disease parameters with systemic medical conditions and tobacco use. J Clin Periodontol. 2004;31(8):625-32.

2. Aarabi G, Schnabel RB, Heydecke G, Seedorf U. Potential impact of oral inflammations on cardiac functions and atrial fibrillation. Biomolecules. 2018;8(3):66. biom8030066. https://doi.org/10.3390/

3. Cheng Z, Meade J, Mankia K, Emery P, Devine DA. Periodontal disease and periodontal bacteria as triggers for rheumatoid arthritis. Best Pract Res Clin Rheumatol. 2017;31(1):19-30.

4. Heredia PA, Lafaurie GI, Bautista-Molano W, et al. Predictive factors related to the progression of periodontal disease in patients with early rheumatoid arthritis: a cohort study. BMC Oral Health. 2019;19(1):240.

5. Loutan L, Alpizar-Rodriguez D, Courvoisier DS, Finckh A, Mombelli A, Giannopoulou C. Periodontal status correlates with anti-citrullinated protein antibodies in first-degree relatives of individuals with rheumatoid arthritis. J Clin Periodontol. 2019;46(7):690-8.

6. Ryan ME, Carnu O, Kamer A. The influence of diabetes on the periodontal tissues. J Am Dent Assoc. 2003;134 Spec No:34S-40S. https://doi.org/10. 14219/jada.archive.2003.0370.

7. Linden GJ, Lyons A, Scannapieco FA. Periodontal systemic associations: review of the evidence. J Clin Periodontol. 2013;40(Suppl 14):S8-19.

8. Tsioufis C, Kasiakogias A, Thomopoulos C, Stefanadis C. Periodontitis and blood pressure: the 
concept of dental hypertension. Atherosclerosis. 2011;219(1):1-9.

9. Mashalkar VN, Suragimath G, Zope SA, Varma SA. A cross-sectional study to assess and correlate osteoporosis and periodontitis among postmenopausal women: a dual energy X-ray absorptiometry study. J Midlife Health. 2018;9(1):2-7.

10. Yamada J, Amar S, Petrungaro P. Psoriasis-associated periodontitis: a case report. J Periodontol. 1992;63(10):854-7.

11. Antal M, Braunitzer G, Mattheos N, Gyulai R, Nagy K. Smoking as a permissive factor of periodontal disease in psoriasis. PLoS ONE. 2014;9(3):e92333.

12. Hobbins S, Chapple IL, Sapey E, Stockley RA. Is periodontitis a comorbidity of COPD or can associations be explained by shared risk factors/behaviors? Int J Chron Obstruct Pulmon Dis. 2017;12: 1339-49.

13. Radnai M, Gorzo I, Nagy E, Urban E, Novak T, Pal A. A possible association between preterm birth and early periodontitis. A pilot study. J Clin Periodontol. 2004;31(9):736-41.

14. Marakoglu I, Gursoy UK, Marakoglu K, Cakmak H, Ataoglu T. Periodontitis as a risk factor for preterm low birth weight. Yonsei Med J. 2008;49(2):200-3.

15. Battancs E, Gorzo I, Pal A, et al. Pregnant women's oral hygiene knowledge and habits after the second millennium in South-East Hungary. Fogorv Sz. 2011;104(3):75-9.

16. Fernandes JK, Wiegand RE, Salinas CF, et al. Periodontal disease status in gullah african americans with type 2 diabetes living in South Carolina. J Periodontol. 2009;80(7):1062-8.

17. Seymour GJ, Powell RN, Davies WI. The immunopathogenesis of progressive chronic inflammatory periodontal disease. J Oral Pathol. 1979;8(5):249-65.

18. Hirschfeld J, Howait M, Movila A, et al. Assessment of the involvement of the macrophage migration inhibitory factor-glucocorticoid regulatory dyad in the expression of matrix metalloproteinase- 2 during periodontitis. Eur J Oral Sci. 2017;125(5): 345-54.

19. Kalakonda B, Koppolu P, Baroudi K, Mishra A. Periodontal systemic connections-novel associations-a review of the evidence with implications for medical practitioners. Int J Health Sci (Qassim). 2016;10(2):293-307.
20. Graves DT, Kayal RA. Diabetic complications and dysregulated innate immunity. Front Biosci. 2008;13:1227-399.

21. Pham MN, Hawa MI, Pfleger C, et al. Pro- and antiinflammatory cytokines in latent autoimmune diabetes in adults, type 1 and type 2 diabetes patients: action LADA 4. Diabetologia. 2011;54(7): 1630-8.

22. The Emerging Risk Factors Collaboration, Sarwar N, Gao P, et al. Diabetes mellitus, fasting blood glucose concentration, and risk of vascular disease: a collaborative meta-analysis of 102 prospective studies. Lancet. 2010;375(9733):2215-22.

23. Loe H. Periodontal disease. The sixth complication of diabetes mellitus. Diabetes Care. 1993;16(1): 329-34.

24. Graziani F, Gennai S, Solini A, Petrini M. A systematic review and meta-analysis of epidemiologic observational evidence on the effect of periodontitis on diabetes an update of the EFP-AAP review. J Clin Periodontol. 2018;45(2):167-87.

25. Baeza M, Morales A, Cisterna C, et al. Effect of periodontal treatment in patients with periodontitis and diabetes: systematic review and meta-analysis. J Appl Oral Sci. 2020;28:e20190248.

26. Mataftsi M, Koukos G, Sakellari D. Prevalence of undiagnosed diabetes and pre-diabetes in chronic periodontitis patients assessed by an HbA1c chairside screening protocol. Clin Oral Investig. 2019;23(12):4365-70.

27. Lappin DF, Eapen B, Robertson D, Young J, Hodge PJ. Markers of bone destruction and formation and periodontitis in type 1 diabetes mellitus. J Clin Periodontol. 2009;36(8):634-41.

28. Salvi GE, Franco LM, Braun TM, et al. Pro-inflammatory biomarkers during experimental gingivitis in patients with type 1 diabetes mellitus: a proof-ofconcept study. J Clin Periodontol. 2010;37(1):9-16.

29. Sanz M, Ceriello A, Buysschaert M, et al. Scientific evidence on the links between periodontal diseases and diabetes: Consensus report and guidelines of the joint workshop on periodontal diseases and diabetes by the International Diabetes Federation and the European Federation of Periodontology. J Clin Periodontol. 2018;45(2):138-49.

30. Lim LP, Tay FB, Sum CF, Thai AC. Relationship between markers of metabolic control and inflammation on severity of periodontal disease in patients with diabetes mellitus. J Clin Periodontol. 2007;34(2):118-23. 
31. Taboza ZA, Costa KL, Silveira VR, et al. Periodontitis, edentulism and glycemic control in patients with type 2 diabetes: a cross-sectional study. BMJ Open Diabetes Res Care. 2018;6(1):e000453.

32. Lalla E, Cheng B, Lal S, et al. Diabetes mellitus promotes periodontal destruction in children. J Clin Periodontol. 2007;34(4):294-8.

33. Hodge PJ, Robertson D, Paterson K, Smith GL, Creanor S, Sherriff A. Periodontitis in non-smoking type 1 diabetic adults: a cross-sectional study. J Clin Periodontol. 2012;39(1):20-9.

34. Costa FO, Miranda Cota LO, Pereira Lages EJ, et al. Progression of periodontitis and tooth loss associated with glycemic control in individuals undergoing periodontal maintenance therapy: a 5-year follow-up study. J Periodontol. 2013;84(5):595-605.

35. Garcia D, Tarima S, Okunseri C. Periodontitis and glycemic control in diabetes: NHANES 2009 to 2012. J Periodontol. 2015;86(4):499-506.

36. Kim EK, Lee SG, Choi YH, et al. Association between diabetes-related factors and clinical periodontal parameters in type- 2 diabetes mellitus. BMC Oral Health. 2013;13:64.

37. Preshaw PM, Alba AL, Herrera D, et al. Periodontitis and diabetes: a two-way relationship. Diabetologia. 2012;55(1):21-31.

38. Casanova L, Hughes FJ, Preshaw PM. Diabetes and periodontal disease: a two-way relationship. $\mathrm{Br}$ Dent J. 2014;217(8):433-7.

39. Taylor GW. Bidirectional interrelationships between diabetes and periodontal diseases: an epidemiologic perspective. Ann Periodontol. 2001;6(1):99-112.

40. Correa FO, Goncalves D, Figueredo CM, Bastos AS, Gustafsson A, Orrico SR. Effect of periodontal treatment on metabolic control, systemic inflammation and cytokines in patients with type 2 diabetes. J Clin Periodontol. 2010;37(1):53-8.

41. Engebretson S, Kocher T. Evidence that periodontal treatment improves diabetes outcomes: a systematic review and meta-analysis. J Clin Periodontol. 2013;40(Suppl 14):S153-S163163.

42. Koromantzos PA, Makrilakis K, Dereka X, Katsilambros N, Vrotsos IA, Madianos PN. A randomized, controlled trial on the effect of non-surgical periodontal therapy in patients with type 2 diabetes. Part I: effect on periodontal status and glycaemic control. J Clin Periodontol. 2011;38(2):142-7.

43. Quintero AJ, Chaparro A, Quirynen M, et al. Effect of two periodontal treatment modalities in patients with uncontrolled type 2 diabetes mellitus: a randomized clinical trial. J Clin Periodontol. 2018;45(9):1098-106.

44. Kocher T, Holtfreter B, Petersmann A, et al. Effect of periodontal treatment on HbA1c among patients with prediabetes. J Dent Res. 2019;98(2):171-9.

45. Parker DR, Fallone D, Martin RA, et al. The relation between smoking status and medical conditions among incarcerated adults. J Addict Med. 2014;8(2): $90-5$.

46. Heydarpour P, Manouchehrinia A, Beiki O, et al. Smoking and worsening disability in multiple sclerosis: a meta-analysis. Acta Neurol Scand. 2018;138(1):62-9.

47. Fagard RH, Nilsson PM. Smoking and diabetes-the double health hazard! Prim Care Diabetes. 2009;3(4):205-9.

48. Cignarelli M, Lamacchia O, Di Paolo S, Gesualdo L. Cigarette smoking and kidney dysfunction in diabetes mellitus. J Nephrol. 2008;21(2):180-9.

49. Obradovic R, Kesic LJ, Gasic J, Petrovic M, Zivkovic N. Role of smoking in periodontal disease among diabetic patients. West Indian Med J. 2012;61(1): 98-101.

50. Gupta N, Gupta ND, Garg S, et al. The effect of type 2 diabetes mellitus and smoking on periodontal parameters and salivary matrix metalloproteinase- 8 levels. J Oral Sci. 2016;58(1):1-6.

51. Orbak R, Tezel A, Canakci V, Demir T. The influence of smoking and non-insulin-dependent diabetes mellitus on periodontal disease. J Int Med Res. 2002;30(2):116-25.

52. Javed F, Al-Kheraif AA, Salazar-Lazo K, et al. Periodontal inflammatory conditions among smokers and never-smokers with and without type 2 diabetes mellitus. J Periodontol. 2015;86(7):839-46.

53. Antal M, Battancs E, Bocskai M, Braunitzer G, Kovacs L. An observation on the severity of periodontal disease in past cigarette smokers suffering from rheumatoid arthritis- evidence for a long-term effect of cigarette smoke exposure? BMC Oral Health. 2018;18(1):82.

54. Genco RJ, Borgnakke WS. Risk factors for periodontal disease. Periodontol 2000. 2013;62(1): 59-94.

55. Greene JC, Vermillion JR. The simplified oral hygiene index. J Am Dent Assoc. 1964;68:7-13.

56. Faul F, Erdfelder E, Lang AG, Buchner A. G*Power 3: a flexible statistical power analysis program for the 
social, behavioral, and biomedical sciences. Behav Res Methods. 2007;39(2):175-91.

57. American DA. Diagnosis and classification of diabetes mellitus. Diabetes Care. 2011;34(Suppl 1): S62-S69.

58. Lin CY, Chen F, Hariri A, et al. Photoacoustic imaging for noninvasive periodontal probing depth measurements. J Dent Res. 2018;97(1):23-30.

59. Leroy R, Eaton KA, Savage A. Methodological issues in epidemiological studies of periodontitis-how can it be improved? BMC Oral Health. 2010;10:8.

60. Souto MLS, Rovai ES, Ganhito JA, Holzhausen M, Chambrone L, Pannuti CM. Efficacy of systemic antibiotics in nonsurgical periodontal therapy for diabetic subjects: a systematic review and metaanalysis. Int Dent J. 2018;68(4):207-20.

61. Nibali L, Krajewski A, Donos N, et al. The effect of furcation involvement on tooth loss in a population without regular periodontal therapy. J Clin Periodontol. 2017;44(8):813-21.

62. Chang SA. Smoking and type 2 diabetes mellitus. Diabetes Metab J. 2012;36(6):399-403.

63. Haire-Joshu D, Glasgow RE, Tibbs TL. Smoking and diabetes. Diabetes Care. 1999;22(11):1887-988.
64. Leite FRM, Nascimento GG, Scheutz F, Lopez R. Effect of smoking on periodontitis: a systematic review and meta-regression. Am J Prev Med. 2018;54(6):831-41.

65. Huang J, Xiao Y, Xu A, Zhou Z. Neutrophils in type 1 diabetes. J Diabetes Investig. 2016;7(5):652-63.

66. Abdullah A, Peeters A, de Courten M, Stoelwinder J. The magnitude of association between overweight and obesity and the risk of diabetes: a meta-analysis of prospective cohort studies. Diabetes Res Clin Pract. 2010;89(3):309-19.

67. Taylor JJ, Preshaw PM, Lalla E. A review of the evidence for pathogenic mechanisms that may link periodontitis and diabetes. J Clin Periodontol. 2013;40(Suppl 14):S113-S134.

68. Mauri-Obradors E, Merlos A, Estrugo-Devesa A, Jane-Salas E, Lopez-Lopez J, Vinas M. Benefits of non-surgical periodontal treatment in patients with type 2 diabetes mellitus and chronic periodontitis: a randomized controlled trial. J Clin Periodontol. 2018;45(3):345-53.

69. World Health Organization. Use of glycated haemoglobin (HbA1c) in the diagnosis of diabetes mellitus. Abbreviated report of a WHO consultation. Geneva: World Health Organization; 2011. 
II. 


\title{
An observation on the severity of periodontal disease in past cigarette smokers suffering from rheumatoid arthritis- evidence for a long-term effect of cigarette smoke exposure?
}

\author{
Márk Antal ${ }^{1 *}$, Emese Battancs ${ }^{1}$, Márta Bocskai ${ }^{2}$, Gábor Braunitzer $^{3}$ and László Kovács ${ }^{2}$
}

\begin{abstract}
Background: Rheumatoid arthritis (RA) and cigarette smoking are both risk factors for periodontal disease (PD). Previous research suggests that systemic inflammatory conditions and cigarette smoking may act in synergy, and their co-occurrence leads to a much higher risk of developing severe stage PD than what the combination of their individual risks would suggest. We originally sought to test this in the case of RA, but it turned out that the majority of our patients were former smokers, who smoked for prolonged periods in the past. For that reason, we decided to shift our focus toward the possible effects of past chronic cigarette smoke exposure.
\end{abstract}

Methods: The data of 73 RA patients and 77 healthy controls were analyzed. The participants received a full-mouth periodontal examination to determine their periodontal status. Rheumatological indices and data on past tobacco use were also recorded. Both the patient and the control groups were divided into former smoker and non-smoker subgroups for the analyses. Non-smoker controls were used as the reference group.

Results: In the control group, smoking in history increased the odds of developing both the moderate and the severe stages of PD, but the change was not statistically significant. RA significantly, increased the odds of developing both stages in itself, but the highest odds were seen in the former smoker RA group.

Conclusion: Based on this surprising observation of ours, we hypothesize that chronic cigarette smoke might bring about permanent changes in the periodontal tissues, leading to their hypersensitivity to inflammatory challenges.

Keywords: Rheumatoid arthritis, Periodontal disease, Chronic inflammation, Late sequelae, Tobacco smoking

\section{Background}

The connection between periodontal disease (PD) and various systemic conditions of an autoimmune/dysimmune background is well documented [1-5]. Rheumatoid arthritis (RA) is an immune mediated disease with a particularly well established link to PD [6-9]. While the exact immunological mechanisms have not been clarified, there is evidence to suggest that the presence of citrullinated proteins (and antibodies against them) is the link [10-12].

\footnotetext{
* Correspondence: antal.mark@stoma.szote.u-szeged.hu

${ }^{1}$ Faculty of Dentistry, Department of Aesthetic and Operative Dentistry,

University of Szeged, 6720 Tisza Lajos körút, Szeged 64, Hungary

Full list of author information is available at the end of the article
}

In this respect, the role of the periodontal pathogen, Porphyromonas gingivalis is emphasized, the only periodontal pathogen that expresses the citrullinating enzyme peptidyl-arginine deiminase (PPAD) $[9,13,14]$. Compared to the general population, subjects with $\mathrm{PD}$ are at an increased risk of developing RA, and vice versa $[9,15]$, which suggests that once they are established, they mutually aggravate each other.

Cigarette smoking is a known risk factor for both $\mathrm{PD}$ [16-18] and RA [19-21]. Cigarette smoking promotes oral bacterial colonization [22] and smoking itself has been shown to promote citrullination [23], evidenced by the fact that an association was found between tobacco 
exposure and anti-cyclic citrullinated peptide (antiCCP) titers in RA patients [24]. It follows that cigarette smoking may be an additional aggravating factor in both PD and RA, especially when the two conditions are comorbid.

In 2014, we published a study about the effects of cigarette smoking on the severity of PD in psoriasis [25]. In that study, we found that while both psoriasis and smoking significantly elevated the odds that the individual will develop advanced PD, when both risk factors were present, the odds multiplied, well beyond the combined odds. We concluded that cigarette smoking probably acted as a permissive factor, and we articulated a hypothesis about the possible role of toll-like receptor 4 (TLR-4). The hypothesis was that smoking exerts this effect through the upregulation of TLR-4.

In their review [26], Baka and co-workers point out that as cigarette smoking promotes bacterial colonization, it may well be that smokers are exposed to an increased burden of $P$. gingivalis, whereby they are constantly exposed to a potent antigen.

Based on these premises, we wished to find out about if smoking acts as a booster of periodontal deterioration also in the context of RA. This is an important question with practical bearings. For instance, severe PD was reported to hamper the efficacy of anti-TNF (tumor necrosis factor) therapy [27].

To answer the question, we collected data on $82 \mathrm{RA}$ patients and 100 controls who met all the inclusion and exclusion criteria and also gave their informed consent. At this point, though, we were faced with a difficulty: most of our patients turned out to be non-smokers (NS). Only eight of them smoked at the time of the study, and the rest had either quit or never ever smoked in their lives. The majority of our patient sample, therefore, consisted of non-smokers and former smokers (FS) who had quit smoking long before.

While we have a wealth of information about the immunological consequences of current smoking [28-31], we know almost nothing about the permanent immunological changes that chronic exposure to cigarette smoke may bring about - and that may remain even if the smoker quits. Considering that the majority of our formerly smoking patients had smoked for at least a decade before they quit, and that chronic exposure to cigarette smoke was proven to induce genome level changes [32-34], we decided to shift our focus and concentrate on the effects of past smoking. We hypothesized that the periodontal status of patients with no smoking history would be significantly poorer than that of healthy controls (the effect of RA), and we wished to know if past smoking would be associated with poorer periodontal status to any extent. We were also interested in the relationship between the rheumatological factors and the periodontal status.

\section{Methods}

Both RA patients and healthy controls were recruited on a voluntary basis.

Patients were eligible for the study if they met the 2010 European League against Rheumatism and American College of Rheumatology (EULAR/ACR) criteria for rheumatoid arthritis [35]. Exclusion criteria for both groups were determined based on the literature of the subject and included obesity (body mass index - BMI $\geq 30$ ), excessive alcohol consumption, drug abuse, diabetes mellitus, diseases causing neutropenia and local or systemic inflammatory conditions (other than RA) [36]. Poor oral hygiene, defined as Simplified Oral Health Index (OHI-S)- > 3 [37] was also an exclusion criterion.

Required sample size was calculated with G*Power 3.1. 5. (University of Kiel, Germany), a software designed especially for statistical power and sample size computation [38]. The software allows the computation of achieved statistical power (post-hoc) and required sample size (a priori). As mostly categorical variables were to be analyzed, a priori sample size estimation was performed for crosstabs/chi square/contingency tables, with the following input parameters: effect size $(\mathrm{w}): 0.3 ; \alpha: 0$. 05;power (1- $\beta$ ): 0.9 ; df: 3 . Required sample size turned out to be $n=158$ (for four groups: RA smoker/former smoker; control smoker/former smoker).

RA Patients $(n=82)$ were recruited from among the patients of the Department of Rheumatology, University of Szeged. The control group $(n=100)$ was recruited from among people attending mandatory lung screening in the same city and the same period. After removing the actual smokers from the sample, we were left with 150 participants (73 patients and 77 controls), yielding a statistical power of 0.88 .

The study was approved by the Institutional and Regional Ethics Committee for Medical Biological Research at the University of Szeged (approval No.144/2014), and the study design conformed to the Declaration of Helsinki in all respects. Written informed consent was obtained from all participants.

Demographic and tobacco use data were collected by a questionnaire. Participants were divided into FS and non-smoker groups, based on their self-reported tobacco use in the past. In both the patient and the control groups, a subject was considered a FS if they smoked for at least one year in the past as a habit and without interruption. Sixty-four percent of the FS controls and 74\% of the FS RA patients provided tobacco use information that could be used for the analyses.

The clinical disease severity of PD is still a matter of debate, and several methods are available in the literature [39]. We decided to use the staging proposed by Fernandes and colleagues [40]. The reason for using this 
Table 1 The applied clinical staging and the corresponding pathological/pathophysiological changes [40, 41]

\begin{tabular}{|c|c|}
\hline CLINICAL STAGING (Fernandes et al., 2009) & PATHOLOGY/PATHOPHYSIOLOGY (Ohlrich et al., 2009) \\
\hline $\begin{array}{l}\text { 1.NO CLINICAL SIGNS- no clinical attachment loss } \\
\text { (CAL) or bleeding on probing (BOP) }\end{array}$ & (NO LESION- NOT CLASSIFIED EXPLICITLY IN OHLRICH ET AL.) \\
\hline $\begin{array}{l}\text { (GINGIVITIS-NOT CLASSIFIED EXPLICITLY IN } \\
\text { FERNANDES ET AL.) }\end{array}$ & $\begin{array}{l}\text { 1. INITIAL LESION - up to } 4 \text { days following plaque accumulation. Polymorphonuclear } \\
\text { leukocytes (PMN), complement activation, loss of connective tissue. Mast cells release tumor } \\
\text { necrosis factor alpha, PMNs migrate into the gingival sulcus, but as the bacteria are protected } \\
\text { by the biofilm, abortive phagocytosis occurs. PMNs release lysosomal contents, which leads } \\
\text { to further tissue destruction. }\end{array}$ \\
\hline $\begin{array}{l}\text { 2.EARLY PERIODONTITIS- CAL } \\
\geq 1 \mathrm{~mm} \text { in } \geq 2 \text { teeth }\end{array}$ & $\begin{array}{l}\text { 2. EARLY/STABLE LESION- 7-21 days after plaque accumulation, clinically evident approxi- } \\
\text { mately from day } 12 \text {. Dominantly macrophages and lymphocytes }\left(C D 4^{+}: \mathrm{CD}^{+} 2: 1\right) \text {. } \\
\text { Perivascular inflammatory infiltrate. Intercellular spaces between epithelial cells widen, } \\
\text { bacterial products infiltrate the gingival tissues at a higher rate. Escalation of response. } \\
\text { If plaque removed, tissue remodeling can take place. }\end{array}$ \\
\hline $\begin{array}{l}\text { 3.MODERATE PERIODONTITIS- } 3 \text { sites with CAL } \\
\geq 4 \mathrm{~mm} \text { and at least } 2 \text { sites with } \\
\text { probing depth (PRD) } \geq 3 \mathrm{~mm}\end{array}$ & $\begin{array}{l}\text { 3. ESTABLISHED OR PROGRESSIVE LESION- dominantly a B cell/plasma cell response. High } \\
\text { levels of IL-1 and IL-6: connective tissue loss, breakdown of bone. }\end{array}$ \\
\hline $\begin{array}{l}\text { 4. SEVERE PERIODONTITIS- CAL } \geq 6 \mathrm{~mm} \text { in } \geq 2 \text { teeth } \\
\text { and PRD } \geq 5 \mathrm{~mm} \text { in } \geq 1 \text { site }\end{array}$ & $\begin{array}{l}\text { 4. ADVANCED LESION- Overt loss of attachment. High levels of IL-1, TNF a and } \text { PGE }_{2} \text { stimulate } \\
\text { fibroblasts and macrophages to produce matrix metalloproteases. The junctional epithelium } \\
\text { progresses in apical direction (deepening periodontal pocket). } \\
\text { Oligoclonal Th }\left(C D 4^{+}\right) \text {dominance. }\end{array}$ \\
\hline
\end{tabular}

classification was that its clinical staging matches the pathological/pathophysiological changes in PD very well [41], and that we had had previous experience with it [25]. The staging requires the following parameters to be recorded: bleeding on probing (BOP; the presence or absence of bleeding within $15 \mathrm{~s}$ after probing), probing depth (PRD; in millimeters), and clinical attachment level (CAL; to describe the position of the soft tissue in relation to the cemento-enamel junction). All subjects received a full-mouth examination and their periodontal status was classified into one of the four categories of the staging: healthy(0); early (1); moderate (2); severe (3). For the examination, Williams probes (Hu-Friedy Manufacturing Co., Chicago, USA) were used. Table 1 shows the categories of the applied staging and the corresponding pathological/pathophysiological status. Although there is some lack of overlap in the first stage of the PD, it may not influence any of the results as nor the initial lesion, nor the gingivitis is having real influence on the immune sytem and the gingival health. Gingivitis itself is a reversible form of the disease.
To characterize the patient population from a rheumatological point of view, the following indices and laboratory values were recorded: IgM rheumatoid factor seropositivity and levels (RF) measured with nephelometry, anti-citrullinated peptide antibody (ACPA) seropositivity and levels with antigenic specificity to mutated citrullinated vimentin (aMCV) measured with ELISA, disease activity score (DAS28-ESR) at the latest visit and its average of the past 12 months, and the HAQ-DI disability index. Data on the conventional and biological disease modifying antirheumatic drug (DMARD) and corticosteroid therapy of the patients were also recorded. Laboratory values were determined as part of the routine examinations (i.e. not especially for this study).

We divided the subjects into four groups based on the presence/absence of RA and smoking in the past. To express the odds that a member of a given group develops a given clinical degree of periodontal disease, multinomial logistic regression analysis was conducted and the odds ratios were calculated. In the multinomial

Table 2 Demographic and tobacco use characteristics of the studied groups

\begin{tabular}{llllll}
\hline Group & Sex ratio F(\%):M(\%) & $\begin{array}{l}\text { Smoke-free for } \\
\text { (mean years, SD) }\end{array}$ & $\begin{array}{l}\text { Smoked for } \\
\text { (mean years, SD) }\end{array}$ & $\begin{array}{l}\text { Cigarettes smoked per day } \\
\text { (rounded average, SD) }\end{array}$ & $\begin{array}{l}\text { Age in years } \\
(\text { mean, SD) }\end{array}$ \\
\hline CNS $(n=55)$ & $44(80): 11(20)$ & NA & NA & NA & $55.7(13.3)$ \\
CS $(n=22)$ & $12(54): 10(45)$ & $11.3(12.5)$ & $13.8(10.2)$ & $11(7.9)$ & $58.1(13.5)$ \\
PNS $(n=42)$ & $33(79): 9(21)$ & NA & NA & NA & $56.5(12.7)$ \\
PS $(n=31)$ & $24(77): 7(23)$ & $16.4(12.2)$ & $18.3(11.4)$ & $14(10.2)$ & $59.3(13.6)$ \\
\hline
\end{tabular}

CNS control, never smoked, CS control, used to smoke, PNS patient, never smoked, PS patient, used to smoke 
Table 3 A brief rheumatological characterization of the patient population by smoking in patient history

\begin{tabular}{|c|c|c|}
\hline \multirow[t]{2}{*}{ Rheumatoid factor positivity [> $30 \mathrm{U} / \mathrm{ml}$ n (\%) } & FS & $20(64.5)$ \\
\hline & NS & $24(57.1)$ \\
\hline \multirow[t]{2}{*}{ Anti-citrullinated peptide antibody positivity [> $20 \mathrm{U} / \mathrm{ml}]$ n(\%) } & FS & $20(64.5)$ \\
\hline & NS & $25(59.5)$ \\
\hline \multirow[t]{2}{*}{ Patients on conventional DMARD therapy n (\%) } & FS & $25(80.6)$ \\
\hline & NS & $36(85.7)$ \\
\hline \multirow[t]{2}{*}{ Patients on biological DMARD therapy (\%) } & FS & $17(54.8)$ \\
\hline & NS & $18(42.8)$ \\
\hline \multirow[t]{2}{*}{ DAS28 at visit mean (SD; range) } & FS & $(n=21) 3.10(1.42 ; 0.97-6.52)$ \\
\hline & NS & $(n=35) 2.94(1.30 ; 0.79-6.33)$ \\
\hline \multirow[t]{2}{*}{ Average DAS28 in the previous 12 months mean (SD; range) } & FS & $(n=10) 3.20(1.68 ; 1.38-5.22)$ \\
\hline & NS & $(n=8) 2.41(1.30 ; 1.20-5.30)$ \\
\hline \multirow[t]{2}{*}{ HAQ mean (SD) } & FS & $(n=15) 0.98(0.84)$ \\
\hline & NS & $(n=7) 2.21(0.70)$ \\
\hline
\end{tabular}

FS former smoker, NS never smoked, DMARD disease-modifying antirheumatic drug, DAS28 disease activity score, $H A Q$ score on the health assessment questionnaire for rheumatoid arthritis. Where data from not all patients were available, the actual number of patients is given in parentheses

model, disease severity (healthy, early, moderate, severe) was defined as the outcome variable, group was the factor, and age and sex were covariates. Within-group analyses (Mann-Whitney U tests) were also performed in the patient group, according to the smoking status, to see if past smoking had any effect on the rheumatological indices. For the analyses, SPSS 21.0 (IBM, USA) was used.

\section{Results}

The demographic and tobacco use characteristics of the four studied groups are given in Table 2. It can be seen that the vast majority of the participants were females. This is because RA affects predominantly women and the control group was selected to match the patient group age- and gender-wise as closely as possible.

The within-group comparisons in the patient group did not indicate significant difference in any of the rheumatological indices between FS and non-smokers (data not shown). To test the effect of RF/aMCV positivity on periodontal status, a separate multinomial regression analysis was conducted. While no statistically significant effects were found, seropositivity for RF increased the odds of the moderate stage to 1.65 , and that of the severe stage to 2.51. The rheumatological indices of the patient group are summarized in Table 3.

The periodontal status and CAL data of each group is shown in Table 4. It is noteworthy that while the majority of the cases in both control groups falls into the healthy and early stages, in the patient groups the situation is just the opposite. This tendency is the most remarkable among the patients who used to smoke. $81 \%$ of them were classified as having moderate or severe PD. Note also that in the patient groups nobody was found who could be classified as periodontally healthy.

The results of the multinomial regression analysis are given in Table 5. The analysis indicated no significant influence of either age or sex on periodontal status. Male

Table 4 Periodontal status in the examined groups according to Fernandes et al. (38). Data are given as $n$ (\%, rounded percentages). $\mathrm{CAL}$ values are also shown ( $\mathrm{mm}$, mean $\pm \mathrm{SD}$ ). The conventions are the same as in Table 1

\begin{tabular}{|c|c|c|c|c|c|c|c|c|}
\hline & \multicolumn{4}{|l|}{ RA } & \multicolumn{4}{|l|}{ Control } \\
\hline & $n$ & & $C A L$ & & $n$ & & $C A L$ & \\
\hline \multirow[t]{3}{*}{ Total } & 73 & & $3.55( \pm$ & & 77 & & $2.03( \pm 1$. & \\
\hline & PNS & & PS & & CNS & & CS & \\
\hline & $n$ & CAL & $n$ & $C A L$ & $n$ & CAL & $n$ & CAL \\
\hline Total & 42 & $3.18( \pm 1.39)$ & 31 & $4.06( \pm 1.79)$ & 55 & $2.08( \pm 1.26)$ & 22 & $1.91( \pm 0.89)$ \\
\hline Healthy & 0 & NA & 0 & NA & $8(15)$ & $0.67( \pm 0.30)$ & $4(18)$ & $0.76( \pm 0.40)$ \\
\hline Early & $12(29)$ & $1.81( \pm 0.21)$ & $6(19)$ & $1.89( \pm 0.31)$ & $30(55)$ & $1.52( \pm 0.39)$ & $12(55)$ & $1.76( \pm 0.37)$ \\
\hline Modrate & $22(52)$ & $3.07( \pm 0.32)$ & 12 (39) & $3.50( \pm 0.89)$ & $13(24)$ & $3.35( \pm 0.21)$ & $5(23)$ & $3.19( \pm 0.25)$ \\
\hline Severe & $8(19)$ & $5.52( \pm 1.21)$ & $13(42)$ & $5.57( \pm 1.46)$ & $4(7)$ & $4.99( \pm 0.14)$ & $1(5)$ & $4.72( \pm \mathrm{NA})$ \\
\hline
\end{tabular}


Table 5 Results of the multinomial regression analysis. The odds ratios (Exp(B)) express the odds that a member of the given group develops the given stage of periodontal disease. Controls who never smoked and early stage periodontal disease served as reference (as no periodontally healthy individuals were found in the patient group, healthy could not be used as reference). B: correlation coefficient; df: degrees of freedom

\begin{tabular}{|c|c|c|c|c|c|c|}
\hline \multicolumn{2}{|c|}{ Periodontal status (reference: early) } & \multirow{2}{*}{$\frac{B}{1.529}$} & \multirow{2}{*}{$\frac{d f}{1}$} & \multirow{2}{*}{$\frac{\text { Sig. }}{0.011}$} & \multirow{2}{*}{$\frac{\operatorname{Exp}(B)}{4.615}$} & \multirow{2}{*}{$\frac{95 \% \mathrm{Cl} \text { for } \operatorname{Exp}(\mathrm{B})}{1.423-14.966}$} \\
\hline moderate & RA- used to smoke & & & & & \\
\hline & RA- never smoked & 1.442 & 1 & 0.003 & 4.231 & $1.623-11.030$ \\
\hline & Control- used to smoke & 0.932 & 1 & 0.090 & 2.538 & $0.866-7.442$ \\
\hline & Control-never smoked & - & - & - & - & - \\
\hline & Male sex & 0.223 & 1 & 0.643 & 1.250 & $0.487-3.212$ \\
\hline & Age & 0.002 & 1 & 0.896 & 1.002 & \\
\hline \multirow[t]{6}{*}{ severe } & RA- used to smoke & 2.788 & 1 & 0.000 & 16.250 & $3.917-67.412$ \\
\hline & RA- never smoked & 1.609 & 1 & 0.022 & 5.000 & $1.265-19.762$ \\
\hline & Control- used to smoke & 0.405 & 1 & 0.666 & 1.500 & $0.238-9.465$ \\
\hline & Control-never smoked & - & - & - & - & - \\
\hline & Male sex & 0.839 & 1 & 0.867 & 2.315 & $0.703-7.619$ \\
\hline & Age & 0.028 & 1 & 0.176 & 1.029 & $0.972-1.033$ \\
\hline
\end{tabular}

sex appears to be associated with an increased risk for both the moderate and the severe stages, but given the under-representation of the male sex in this study, we would not draw conclusions from this. As for the odds of developing the moderate or severe stages, these were significantly higher in both patient groups for both stages as compared to controls who never smoked. Controls who used to smoke did not have significantly higher odds to develop any of these stages than controls who never smoked, while an increment was definitely seen. The highest significant odds ratio for the severe stage (16.25) was found in the RA group of FS.

\section{Discussion}

A part of these findings is merely the corroboration of known facts. RA has been known as a risk factor for PD for some time [6-8], and our results demonstrate the same: the presence of RA in itself is enough to significantly increase the odds that the patient will develop a more severe stage of PD.

We also found that past smoking did not have a significant effect on any of the rheumatological indices and that there was no association between these indices and periodontal status. The lack of the effect of past smoking on the rheumatological status as expressed by these indices might be best explained by the time passed since the patient stopped smoking. While cigarette smoke must have been an extra immunological stimulus while the patient was still smoking, and it might as well have boosted the immunological memory against citrullinated proteins [42], these effects are unlikely to be reflected in indices characterizing a much narrower time window.

How come that no association was found between the specific RA indices and the periodontal status, while, as pointed out before, being in the RA group in itself significantly increased the odds of the more severe PD stages? Given that other studies describing larger populations found significant association with rheumatoid factor positivity and anti-citrullinated peptide antibody production [43, 44], we think that our sample size was probably too small to allow reliable assessment at the level of the individual indices, considering their greater variability.

The main finding of this study, however, is also the most difficult to explain. The finding that the FS RA patients had the highest and significant odds ratio for the severe stage of PD is really an unexpected one. From the results it appears that the effect is not mediated by the actual rheumatological status, the presence of RA with a longer period of cigarette smoke exposure in the past is enough. This suggests that long-term cigarette smoking might permanently sensitize the periodontium, but at this point we could only speculate about the possible mechanisms, and it is because of that reason that we put this up for debate.

\section{Conclusions}

While this study definitely has its limitations, we think that our quasi-accidental finding about the effect of past smoking on periodontal health in RA deserves attention. This finding implies that long-term exposure to cigarette smoke might have a permanent sensitizing effect on the human periodontal tissues, which is not reversible by quitting smoking.

\section{Abbrevations}

ACP: Anti-citrullinated peptide antibody; aMCV: Mutated citrullinated vimentin; anti-CCP: Anti-cyclic citrullinated peptide; anti-TNF: Anti-tumor necrosis factor; BMl: Body mass index; BOP: Bleeding on probing; 
CAL: Clinical attachment level; CNS: Control, never smoked; CS: Control, used to smoke; DAS28-ESR: Disease activity score; FS: Former smokers; NS: Nonsmokers; OHI-S: Simplified Oral Health Index; PD: Periodontal disease; PNS: Patient, never smoked; PPAD: Peptidyl-arginine deiminase; PRD: Probing depth; PS: Patient, used to smoke; RA: Rheumatoid arthritis; RF: Rheumatoid factor; TLR-4: Toll-like receptor 4

\section{Availability of data and materials}

The datasets used and/or analysed during the current study available from the corresponding author on reasonable request.

\section{Authors' contributions}

MA organized the study; MA and EB performed the periodontal examinations and recorded patient data; $\mathrm{MB}$ and LK performed the rheumatological examinations and recorded patient data; GB performed the data analysis; $E B, M B, L K, M A$ and $G B$ prepared the manuscript. All authors have read and approved the final version of the manuscript.

\section{Ethics approval and consent to participate}

The study was approved by the Institutional and Regional Ethics Committee for Medical Biological Research at the University of Szeged (approval No.144/ 2014), and the study design conformed to the Declaration of Helsinki in all respects. Written informed consent was obtained from all participants.

\section{Competing interests}

The authors declare that they have no competing interests.

\section{Publisher's Note}

Springer Nature remains neutral with regard to jurisdictional claims in published maps and institutional affiliations.

\section{Author details}

${ }^{1}$ Faculty of Dentistry, Department of Aesthetic and Operative Dentistry, University of Szeged, 6720 Tisza Lajos körút, Szeged 64, Hungary. ${ }^{2}$ Faculty of Medicine, Department of Rheumatology and Immunology, University of Szeged, 6725 Kálvária sugárút, Szeged 57, Hungary. ${ }^{3}$ Laboratory for Perception \& Cognition and Clinical Neuroscience, Nyírő Gyula Hospital, 1135 Lehel utca, Budapest 59, Hungary.

\section{Received: 4 May 2017 Accepted: 17 April 2018}

\section{Published online: 10 May 2018}

\section{References}

1. Kim J, Amar S. Periodontal disease and systemic conditions: a bidirectional relationship. Odontology. 2006;94(1):10-21.

2. Grossi SG, Genco RJ. Periodontal disease and diabetes mellitus: a two-way relationship. Ann Periodontol. 1998;3(1):51-61.

3. Shlossman M. Diabetes mellitus and periodontal disease-a current perspective. Compend. 1994;15(8):1018. 1020-1014 passim; quiz 1032

4. Preus HR, Khanifam P, Kolltveit K, Mork C, Gjermo P. Periodontitis in psoriasis patients: a blinded, case-controlled study. Acta Odontol Scand. 2010;68(3):165-70.

5. Shlossman M, Knowler WC, Pettitt DJ, Genco RJ. Type 2 diabetes mellitus and periodontal disease. J Am Dent Assoc. 1990;121(4):532-6.

6. Mercado F, Marshall RI, Klestov AC, Bartold PM. Is there a relationship between rheumatoid arthritis and periodontal disease? J Clin Periodontol. 2000:27(4):267-72

7. Mercado FB, Marshall RI, Bartold PM. Inter-relationships between rheumatoid arthritis and periodontal disease. A review. J Clin Periodontol. 2003;30(9):761-72

8. Mercado FB, Marshall RI, Klestov AC, Bartold PM. Relationship between rheumatoid arthritis and periodontitis. J Periodontol. 2001;72(6):779-87.

9. Koziel J, Mydel P, Potempa J. The link between periodontal disease and rheumatoid arthritis: an updated review. Curr Rheumatol Rep. 2014; 16(3):408.

10. Nesse W, Westra J, van der Wal JE, Abbas F, Nicholas AP, Vissink A, Brouwer $E$. The periodontium of periodontitis patients contains citrullinated proteins which may play a role in ACPA (anti-citrullinated protein antibody) formation. J Clin Periodontol. 2012;39(7):599-607.
11. Detert J, Pischon N, Burmester GR, Buttgereit F. The association between rheumatoid arthritis and periodontal disease. Arthritis Res Ther. 2010;12(5):218.

12. Lundberg K, Wegner N, Yucel-Lindberg T, Venables PJ. Periodontitis in RAthe citrullinated enolase connection. Nat Rev Rheumatol. 2010;6(12):727-30.

13. Hendler A, Mulli TK, Hughes FJ, Perrett D, Bombardieri M, Houri-Haddad Y, Weiss El, Nissim A. Involvement of autoimmunity in the pathogenesis of aggressive periodontitis. J Dent Res. 2010;89(12):1389-94.

14. Wegner N, Wait R, Sroka A, Eick S, Nguyen KA, Lundberg K, Kinloch A, Culshaw S, Potempa J, Venables PJ. Peptidylarginine deiminase from Porphyromonas gingivalis citrullinates human fibrinogen and alpha-enolase: implications for autoimmunity in rheumatoid arthritis. Arthritis Rheum. 2010; 62(9):2662-72.

15. Pons-Fuster A, Rodriguez Agudo C, Galvez Munoz P, Saiz Cuenca E, Pina Perez FM, Lopez-Jornet P. Clinical evaluation of periodontal disease in patients with rheumatoid arthritis: a cross-sectional study. Quintessence Int. 2015:46(9):817-22

16. Bergstrom J. Cigarette smoking as risk factor in chronic periodontal disease. Community Dent Oral Epidemiol. 1989:17(5):245-7.

17. Tonetti MS. Cigarette smoking and periodontal diseases: etiology and management of disease. Ann Periodontol. 1998;3(1):88-101.

18. Martinez-Canut P, Lorca A, Magan R. Smoking and periodontal disease severity. J Clin Periodontol. 1995;22(10):743-9.

19. Heliovaara M, Aho K, Aromaa A, Knekt P, Reunanen A. Smoking and risk of rheumatoid arthritis. J Rheumatol. 1993:20(11):1830-5.

20. Hazes JM, Dijkmans BA, Vandenbroucke JP, de Vries RR, Cats A. Lifestyle and the risk of rheumatoid arthritis: cigarette smoking and alcohol consumption. Ann Rheum Dis. 1990;49(12):980-2.

21. Costenbader KH, Karlson EW. Cigarette smoking and autoimmune disease: what can we learn from epidemiology? Lupus. 2006;15(11):737-45.

22. Kumar PS, Matthews CR, Joshi V, de Jager M, Aspiras M. Tobacco smoking affects bacterial acquisition and colonization in oral biofilms. Infect Immun. 2011;79(11):4730-8.

23. Makrygiannakis D, Hermansson M, Ulfgren AK, Nicholas AP, Zendman AJ, Eklund A, Grunewald J, Skold CM, Klareskog L, Catrina Al. Smoking increases peptidylarginine deiminase 2 enzyme expression in human lungs and increases citrullination in BAL cells. Ann Rheum Dis. 2008;67(10):1488-92.

24. Lee DM, Phillips $\mathrm{R}$, Hagan EM, Chibnik LB, Costenbader KH, Schur PH. Quantifying anti-cyclic citrullinated peptide titres: clinical utility and association with tobacco exposure in patients with rheumatoid arthritis. Ann Rheum Dis. 2009;68(2):201-8.

25. Antal M, Braunitzer G, Mattheos N, Gyulai R, Nagy K. Smoking as a permissive factor of periodontal disease in psoriasis. PLoS One. 2014;9(3):e92333.

26. Baka Z, Buzas E, Nagy G. Rheumatoid arthritis and smoking: putting the pieces together. Arthritis Res Ther. 2009;11(4):238.

27. Savioli C, Ribeiro AC, Fabri GM, Calich AL, Carvalho J, Silva CA, Viana VS, Bonfa E, Siqueira JT. Persistent periodontal disease hampers anti-tumor necrosis factor treatment response in rheumatoid arthritis. J Clin Rheumatol. 2012;18(4):180-4.

28. O'Leary SM, Coleman MM, Chew WM, Morrow C, McLaughlin AM, Gleeson LE, O'Sullivan MP, Keane J. Cigarette smoking impairs human pulmonary immunity to Mycobacterium tuberculosis. Am J Respir Crit Care Med. 2014; 190(12):1430-6.

29. Lee J, Taneja V Vassallo R. Cigarette smoking and inflammation: cellular and molecular mechanisms. J Dent Res. 2012;91(2):142-9.

30. Arnson $Y$, Shoenfeld $Y$, Amital H. Effects of tobacco smoke on immunity, inflammation and autoimmunity. J Autoimmun. 2010;34(3):J258-65.

31. Morris GF, Danchuk S, Wang Y, Xu B, Rando RJ, Brody AR, Shan B, Sullivan $D E$. Cigarette smoke represses the innate immune response to asbestos. Physiol Rep. 2015;3(12). https://doi.org/10.14814/phy2.12652.

32. Lee KW, Pausova Z. Cigarette smoking and DNA methylation. Front Genet. 2013:4:132.

33. Dogan MV, Shields B, Cutrona C, Gao L, Gibbons FX, Simons R, Monick M, Brody GH, Tan K, Beach SR, et al. The effect of smoking on DNA methylation of peripheral blood mononuclear cells from African American women. BMC Genomics. 2014;15:151

34. Zeilinger S, Kuhnel B, Klopp N, Baurecht H, Kleinschmidt A, Gieger C, Weidinger S, Lattka E, Adamski J, Peters A, et al. Tobacco smoking leads to extensive genome-wide changes in DNA methylation. PLoS One. 2013;8(5):e63812. 
35. Aletaha D, Neogi T, Silman AJ, Funovits J, Felson DT, Bingham CO 3rd Birnbaum NS, Burmester GR, Bykerk VP, Cohen MD, et al. Rheumatoid arthritis classification criteria: an American College of Rheumatology/ European league against rheumatism collaborative initiative. Arthritis Rheum. 2010;62(9):2569-81.

36. Genco RJ, Borgnakke WS. Risk factors for periodontal disease. Periodontology 2000. 2013;62(1):59-94.

37. Greene JC, Vermillion JR. The simplified oral hygiene index. J Am Dent Assoc. 1964;68:7-13.

38. Faul F, Erdfelder E, Lang AG, Buchner A. G*power 3: a flexible statistical power analysis program for the social, behavioral, and biomedical sciences. Behav Res Methods. 2007;39(2):175-91.

39. Leroy R, Eaton KA, Savage A. Methodological issues in epidemiological studies of periodontitis-how can it be improved? BMC Oral Health. 2010;10:8.

40. Fernandes JK, Wiegand RE, Salinas CF, Grossi SG, Sanders JJ, Lopes-Virella MF, Slate EH. Periodontal disease status in gullah african americans with type 2 diabetes living in South Carolina. J Periodontol. 2009;80(7):1062-8.

41. Ohlrich EJ, Cullinan MP, Seymour GJ. The immunopathogenesis of periodontal disease. Aust Dent J. 2009;54(Suppl 1):S2-10.

42. James EA, Rieck M, Pieper J, Gebe JA, Yue BB, Tatum M, Peda M, Sandin C, Klareskog L, Malmstrom V, et al. Citrulline-specific Th1 cells are increased in rheumatoid arthritis and their frequency is influenced by disease duration and therapy. Arthritis Rheumatol. 2014:66(7):1712-22.

43. The J, Ebersole JL. Rheumatoid factor (RF) distribution in periodontal disease. J Clin Immunol. 1991;11(3):132-42.

44. Terao C, Asai K, Hashimoto M, Yamazaki T, Ohmura K, Yamaguchi A, Takahashi K, Takei N, Ishii T, Kawaguchi T, et al. Significant association of periodontal disease with anti-citrullinated peptide antibody in a Japanese healthy population - the Nagahama study. J Autoimmun. 2015;59:85-90.

\section{Ready to submit your research? Choose BMC and benefit from:}

- fast, convenient online submission

- thorough peer review by experienced researchers in your field

- rapid publication on acceptance

- support for research data, including large and complex data types

- gold Open Access which fosters wider collaboration and increased citations

- maximum visibility for your research: over $100 \mathrm{M}$ website views per year 